\title{
Botany
}

American Journal of Botany 98(3): 572-592. 2011.

\section{The FUnCTIONAL ROLE OF PRODUCER DIVERSITY IN ECOSYSTEMS ${ }^{1}$}

\author{
Bradley J. Cardinale 2,12 , Kristin L. Matulich ${ }^{3}$, David U. Hooper ${ }^{4}$,

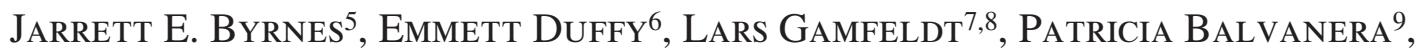 \\ MARY I. O'CONNOR ${ }^{10}$, AND ANDREW GONZALEZ ${ }^{11}$
}

\begin{abstract}
${ }^{2}$ School of Natural Resources and Environment, University of Michigan, 440 Church Street, Ann Arbor, Michigan, 48109 USA; ${ }^{3}$ Department of Ecology \& Evolutionary Biology, University of California-Irvine, 321 Steinhaus Hall, Irvine, California, 92697 USA; ${ }^{4}$ Western Washington University, Department of Biology, Bellingham, Washington, $98225 \mathrm{USA} ;{ }^{5} \mathrm{National}$ Center for Ecological Analyses and Synthesis, 735 State Street, Suite 300, Santa Barbara, California, $93101 \mathrm{USA} ;{ }^{6}$ Virginia Institute of Marine Science, College of William and Mary, P.O. Box 1346, Gloucester Point, Virginia, 23062 USA; ${ }^{7}$ Department of Ecology, Swedish University of Agricultural Sciences, Uppsala, Sweden; ${ }^{8}$ Department of Marine Ecology, University of G(ö)othenburg, Box 461, SE-405 30 Göteborg, Sweden; ${ }^{9}$ Centro de Investigaciones en Ecosistemas, C.P. 58190, Universidad Nacional Autónoma de México; Mexico, D.F., Mexico; ${ }^{10}$ Department of Zoology, University of British Columbia, \#2370-6270 University Blvd., Vancouver, British Columbia, Canada V6T 1Z4; and ${ }^{11}$ McGill University, Department of Biology, 1205 Docteur Penfield, Montreal, Quebec, Canada H3A 1B1
\end{abstract}

\begin{abstract}
Over the past several decades, a rapidly expanding field of research known as biodiversity and ecosystem functioning has begun to quantify how the world's biological diversity can, as an independent variable, control ecological processes that are both essential for, and fundamental to, the functioning of ecosystems. Research in this area has often been justified on grounds that (1) loss of biological diversity ranks among the most pronounced changes to the global environment and that (2) reductions in diversity, and corresponding changes in species composition, could alter important services that ecosystems provide to humanity (e.g., food production, pest/disease control, water purification). Here we review over two decades of experiments that have examined how species richness of primary producers influences the suite of ecological processes that are controlled by plants and algae in terrestrial, marine, and freshwater ecosystems. Using formal meta-analyses, we assess the balance of evidence for eight fundamental questions and corresponding hypotheses about the functional role of producer diversity in ecosystems. These include questions about how primary producer diversity influences the efficiency of resource use and biomass production in ecosystems, how primary producer diversity influences the transfer and recycling of biomass to other trophic groups in a food web, and the number of species and spatial /temporal scales at which diversity effects are most apparent. After summarizing the balance of evidence and stating our own confidence in the conclusions, we outline several new questions that must now be addressed if this field is going to evolve into a predictive science that can help conserve and manage ecological processes in ecosystems.
\end{abstract}

Key words: biodiversity; decomposition; ecosystem functioning; herbivory; nutrient cycling; primary production.

Most fields of natural science have historically treated biological diversity as if it is an epiphenomenon-a simple byproduct of all the physical and chemical variation that promotes diversification and allows species to coexist. Recently, there has been a growing sentiment that this unidirectional perspective represents an incomplete view of biodiversity. Several paradigms in ecology, evolution, paleontology, and biogeography

\footnotetext{
1 Manuscript received 16 September 2010: revision accepted 9 December 2010.

The authors thank the large number of BEF researchers who graciously contributed their data to this synthesis and those who reviewed the data set and conclusions of this paper for accuracy. This work was conducted as a part of the Biodiversity and the Functioning of Ecosystems: Translating Model Experiments into Functional Reality Working Group supported by the National Center for Ecological Analysis and Synthesis, a Center funded by NSF (Grant \#EF-0553768), the University of California, Santa Barbara, and the State of California. Data collection was supported by an NSF grant (DEB-0842009) and Hellman Fellowship to B.J.C. The authors thank two anonymous reviewers for helpful comments on a previous draft of this paper.

12 Author for correspondence (e-mail: bradcard@umich.edu)
}

doi:10.3732/ajb.1000364 have increasingly emphasized that diversity is not just a byproduct of the abiotic environment, but that the numbers and types of organisms directly regulate the physical formation of habitat (Jones et al., 1994; Wright and Jones, 2006), the fluxes of elements that control Earth's biogeochemical cycles (Sterner and Elser, 2002), and the efficiency by which limiting resources are captured and converted into biomass (Tilman, 2000; Naeem, 2002; Hooper et al., 2005). There is now a strong push in many fields of biology to integrate our understanding of the evolutionary and ecological causes of biodiversity with an improved understanding of its functional consequences for ecosystems (Loreau et al., 2001; Cardinale et al., 2009a; Reinhardt et al., 2010).

Ecosystem-level impacts of biodiversity became a focal point of ecological research in the 1990s following a conference of the Scientific Committee on Problems of the Environment (SCOPE) that pulled together information on patterns of diversity and the effects of organism functional traits on ecosystem properties (Schulze and Mooney, 1993). Initial studies showed that reducing the diversity of grassland plants often leads to reduced use of soil nitrogen and lower production of aboveground plant biomass (Naeem et al., 1994; Tilman et al., 1996; Hector et al., 1999). Although the interpretation of these studies 
was controversial, they helped spawn an entire generation of research that has now become colloquially known of as the field of biodiversity and ecosystem functioning (BEF for short). By the end of the 1990s, several hundred studies had examined how the diversity of plants-as well as bacteria, fungi, and animals-influences a variety of ecological processes in most major biomes on the planet.

With the rapid proliferation of data, researchers began to synthesize the balance of evidence linking biodiversity to ecosystem-level processes. As is often the case in an emerging field, early syntheses were based on expert opinions or qualitative summaries and interpretation of data (e.g., Schlapfer et al., 1999; Schwartz et al., 2000; Schmid et al., 2001; Covich et al., 2004; Hooper et al., 2005; Srivastava and Vellend, 2005). But these papers were often inconsistent in their conclusions, despite considerable overlap in the literature reviewed, forcing researchers to confront their hypotheses with more quantitative forms of analyses. Between 2006 and 2008, six formal metaanalyses of the BEF literature were independently published (Balvanera et al., 2006; Cardinale et al., 2006, 2007; Worm et al., 2006; Stachowicz et al., 2007; Cadotte et al., 2008). Each meta-analysis analyzed different subsets of existing data in slightly different ways; yet, the summaries showed surprising consistency in several general conclusions. When averaged across the variety of genotypes, species, or functional groups used in biodiversity experiments, the net effects of diversity loss have been to reduce the efficiency by which communities capture limiting resources (e.g., nutrients, light, prey) and convert those resources into new biomass. Although the results were by no means universal, there appeared to be a striking level of generality in diversity effects across terrestrial, freshwater, and marine ecosystems, and among organisms as divergent as plants and predators.

Since the first generation of meta-analyses was performed, there has been an exponential increase in the number of diversity experiments, and the number of publications has more than tripled since 2006 when earlier databases were put together. The wealth of new data makes it an opportune time to begin a second round of synthesis and re-evaluate our conclusions. Here we present a set of meta-analyses that address eight questions about how species diversity of primary producers influences the ecological properties and processes that producers perform in ecosystems (Table 1, Fig. 1). Our analyses begin with seminal questions that motivated this field of research, including those about how biodiversity influences the efficiency of resource use and production of biomass in ecosystems. We then deal with extended questions on how producer diversity impacts the transfer of mass to higher trophic levels, as well as how it influences the recycling of dead organic matter. We then address questions about the mechanisms that underlie biodiversity

TABLE 1. A summary of the questions and hypotheses addressed in our review and our conclusions regarding the balance of evidence.

\begin{tabular}{ll}
\hline \hline Questions and hypotheses & Evidence (confidence) \\
\hline
\end{tabular}

Q1. How does producer diversity influence the efficiency and productivity of ecosystems?

When averaged across all possible species, the net effect of species loss is to ...

H1a. reduce the standing biomass of a producer community (tissue per area or volume)

H1b. reduce the efficiency by which primary producers assimilate inorganic resources

H1c. reduce rates of primary production $\left(\mathrm{O}_{2}\right.$ produced / $\mathrm{CO}_{2}$ sequestered per unit time)

Q2. Does primary producer diversity modify herbivory?

H2: Herbivore impacts on producer biomass decline as producer richness increases.

Q3. Does primary producer diversity influence the decomposition of litter?

H3: Producer diversity accelerates decomposition, leading to lower stocks of detritus.

Q4. What mechanisms generate effects of producer diversity on ecosystem processes? H4a. Effects of species diversity are due to niche partitioning among species $H 4 b$. Effects of species diversity are due to some form of complementarity

H4c. Effects of species diversity are due to species-specific selection effects

Q5. Do diverse communities "out-perform" their most efficient or productive species? H5a: Diverse polycultures exhibit transgressive overyielding.

H5b: Diverse polycultures capture more nutrients than their most efficient species.

H5c: Litter from a diverse mixture decomposes more quickly than the fastest species.

Q6. What is the shape of the diversity-function relationship?

H6a. Ecosystem processes decline linearly with species loss.

H6b. Ecosystem processes decline exponentially with species loss.

H6c. Ecosystem processes show accelerating declines with increasing species loss.

Q7. What fraction of species do we need to maintain ecosystem processes?

H7. 50\% of species are needed to maintain processes within $75 \%$ of their maximum value.

Q8. Are diversity effects "stronger" at larger spatial and/or longer time scales?

H8a. Effects of producer diversity on biomass increase with temporal scale of experiments.

H8b. Effects of producer diversity on biomass increase with the spatial scale of experiments.

New questions we need to address

Q9. How do diversity effects documented in experiments scale-up to "real" ecosystems?

Q10. Sure... diversity effects are significant. But how strong and important are they compared to other forms of environmental change?

Q11. What types of biological diversity have the greatest impact on ecosystem processes-would conservation and management of ecological functions be better achieved by focusing on genetic, species, functional, or higher levels of diversity?

Q12. How does biodiversity simultaneously impact the suite of ecosystem processes that are required to optimize the "multi-functionality" of diverse ecosystems?
Supported (high)

Supported (high)

Supported (low: min data)

Not-supported (low: min data)

Supported (low: results not consistent among systems)

Insufficient data

Supported (high)

Supported (high)

Not supported (high)

Not supported (high)

Not supported (high)

Not supported (high)

Not supported (high)

Supported (high)

Not supported (low)

Supported (high)

Supported (med)

Evidence

Insufficient evidence to address Insufficient evidence to address

Insufficient evidence to address

Insufficient evidence to address
Fig. 2A, B; Table 2 Fig. 2D, E; Table 2

Fig. 2G, H; Table 2

Fig. 2I, J; Table 2

Fig. 2K, L; Table 2

Fig. 3C, F

Fig. 3D, G

Fig. 2C; Table 2

Fig. 2F; Table 2

Fig. 2M; Table 2

Fig. 5; Table 3

Fig. 6

Fig. 7

Fig. 7 


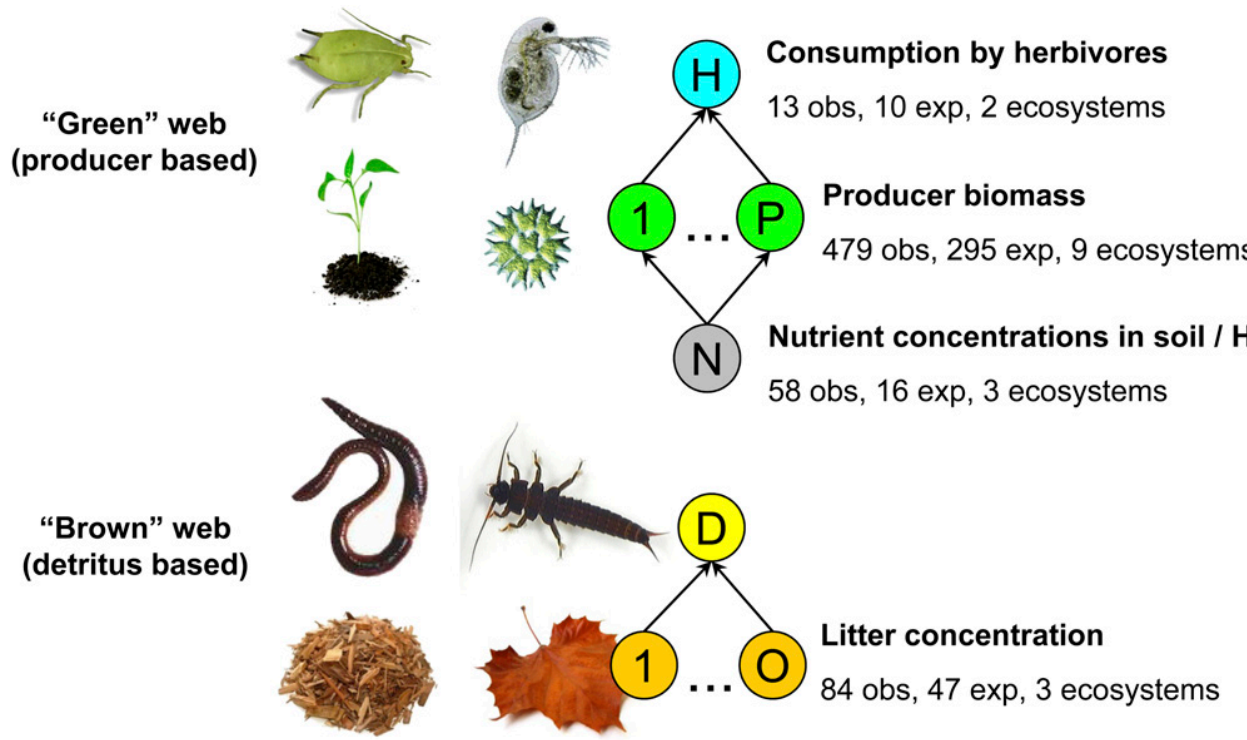

Fig. 1. Summary of the data set and ecological properties used for analyses in this paper. We took the original data set of Cardinale et al. (2009c) and updated it with biodiversity-ecosystem function studies published through 2009. The updated data set included 574 independent manipulations of species richness published in 192 peer-reviewed papers reporting 1417 diversity effect sizes. For purposes of this paper, which focuses on the ecological role of primary producers, we extracted records for 368 independent manipulations of plant or algal species richness that have reported 634 estimates of how the diversity of primary producers impacts the production of plant biomass, uptake of inorganic nutrients, energy flow to herbivores and the decomposition of dead organic matter. The number of observations, experiments, and ecosystems in the data set are shown for each property/process, and these have been divided into processes involving a "green" food web (i.e., fueled by living producers) and a "brown" food web (i.e., fueled by dead organic matter).

effects and about how many species are needed to maximize ecological functions. The last of our eight questions asks what spatial and temporal scales show the strongest diversity effects. Although by no means exhaustive, the eight questions and corresponding hypotheses we address have played a central role in the BEF literature and driven a considerable amount of research over the past 10 years. Yet, the questions and hypotheses have received variable degrees of direct testing.

Our paper has four goals. First, for those questions/hypotheses that have been tested in prior meta-analyses, we use the wealth of new data to refine quantitative estimates for the strength of diversity effects. Second, for questions/hypotheses where prior tests were ambiguous due to scarce data, we provide updated analyses that help solidify conclusions. Third, we use the updated data to offer initial tests of several new hypotheses that have arisen since 2006. Last, we summarize what is currently known and suggest unresolved questions that must now be addressed if the field of BEF research is going to move toward a predictive science that is more useful for conservation and management of the world's ecosystems.

While our analyses update the balance of evidence linking the diversity of primary producers to ecosystem-level functioning, several caveats should be kept in mind. First, the experiments we summarize have focused on primary producers in highly simplified systems that lack the trophic complexity typical of natural ecosystems. This limitation has been discussed at length by authors who have outlined the potential biases and incorrect conclusions that could result from using such simplified, model systems (Duffy, 2002; Duffy et al., 2007; Cardinale et al., 2009b). Second, our review focuses exclusively on studies that have manipulated species richness as the focal aspect of biodiversity. We do not suggest that the simple number of species is the "best" or "most important" aspect of diversity; in fact, growing evidence suggests that diversity at other levels of organization (genetic, functional, or landscape diversity) may have impacts on ecosystem-level processes that equal or exceed those of species richness (Petchey et al., 2004; Hooper et al., 2005; Cadotte et al., 2008; Hughes et al., 2008; Schindler et al., 2010). But the vast majority of experimental manipulations and available data consider species richness as the primary aspect of diversity.

\section{DATA SET AND ANALYSES}

Original data set-The data set used for this summary is an updated version of the one that was originally published by Cardinale et al. (2009c). Because that data set has been used by several prior meta-analyses, all of which have described the methods used to collect and analyze the data (Cardinale et al., 2006, 2007, 2009b; Bruno and Cardinale, 2008; Cadotte et al., 2008; Srivastava et al., 2009), we limit our description of the original data set to only the most salient points.

First, the original data set was generated using a combination of formal and informal searches for relevant studies. Lists of studies were collated from the literature cited sections of several surveys of biodiversity-ecosystem functioning research (Schwartz et al., 2000; Schmid et al., 2001; Covich et al., 2004; Hooper et al., 2005; Srivastava and Vellend, 2005). This was supplemented with a search of the ISI Web of Knowledge database using the keyword sequence species AND (diversity $O R$ richness) AND (community OR ecosystem) AND (function $O R$ functioning $O R$ production $O R$ productivity $O R$ biomass $O R$ predation OR decomposition OR herbivory). To be included in the database, a study had to meet these criteria: 
(1) The study had to focus on species richness rather than any other form of biological diversity.

(2) The study had to be empirical and directly manipulate richness as an independent variable.

(3) The study had to manipulate $\geq 3$ species within a focal trophic group $t$ (producers, herbivores, higher consumers, or detritivores).

(4) The study had to measure the direct effect of richness within a focal trophic group $t$ on (a) the aggregate abundance or biomass (per area or volume) of all species in $t$, (b) the standing concentration of resources used by $t$, or (c) the rate of depletion of resources used by $t$, calculated as instantaneous rates of consumption (e.g., estimates of metabolism), the difference between a known initial and final concentration (e.g., time series of decomposition), or the difference between treatments and 0 -species controls. Other aspects of ecosystem functioning such as temporal stability or invasibility were not considered.

(5) The study could not duplicate data published in another paper. When studies overlapped, data were taken from the paper reporting the most complete information.

(6) If a study used an additive experimental design (i.e., abundance and/or biomass was intentionally confounded with richness to assess nonadditive species interactions), both the observed and expected values had to be reported so that the nonadditive portion of the effect could be calculated and used as the effect attributable to diversity.

The original search identified 216 papers. From these, results were summarized for 164 independent manipulations of species richness reported in 85 papers (note that papers often reported multiple experiments, such as when diversity was independently manipulated at two nutrient levels). Given that many experiments had repeated measurements of the response variables through time, the original data set contained a sum total of 545 estimates of diversity effects on the response variables described in criteria 4.

Update of the data set-We completed an update of the Cardinale et al. (2009c) data set using studies published through September 2009. To identify new studies for inclusion, we (1) repeated the ISI Web of Science keyword search described and augmented this search by searching for additional studies from (2) reference lists of other summaries and meta-analyses that have been published since 2006 (Balvanera et al., 2006; Worm et al., 2006; Stachowicz et al., 2007; Piotto, 2008; Schmid et al., 2009a, b), (3) literature from our own reading lists and bibliography software, and (4) surveys of several expert researchers in the field to inquire about other publications we might have missed. To be included in the updated data set, studies had to meet the same criteria described. To assess the completeness of our search, we generated sampling curves in which we used alterations of our key word sequence, as well as searches through the reference lists of several highly cited papers, to quantify the cumulative number of papers that had been missed. These revealed five papers of 331 papers searched $(1.5 \%)$ that met criteria for inclusion in our database, but which were missed by (1) through (4).

In total, the updated data set summarizes the results of 574 independent manipulations of species richness published in 192 peer-reviewed papers. These experiments have manipulated 541 types of organisms (species, morphotypes, or operational taxonomic units) in 30 biomes on five continents. The data set includes a sum total 1417 observations of how species richness affects the (1) standing stock abundance or biomass of organisms in a focal trophic level $t,(2)$ the standing stock of resources used by $t$, or (3) the efficiency of resource use by $t$. For purposes of this paper, which focuses on the functional role of primary producer diversity, we extracted records that describe how species richness of primary producers impacts four ecological properties: (1) the production of biomass at the producer trophic level, (2) the uptake and sequestration of inorganic resources from soil or water, (3) the impact of herbivores on producer biomass, and (4) the decomposition of litter composed of dead primary producers.

Data analyses - Most of our analyses and conclusions are generated from two types of data summaries- $-\log$ response ratios, and curve fitting. Log response ratios are the most widely used metric for measuring effect sizes in meta-analyses (Hedges et al., 1999). In part, this is because they are dimensionless ratios that allow for relative comparisons of effect sizes (in our case, diversity effect sizes) among experiments that use different methods, take measurements on different scales, etc. We used two log response ratios to make different comparisons. The first response ratio measures what we call the net diversity effect, noted as $L R_{\text {net }} \cdot L_{\text {net }}$ gives the proportional difference in the response variable $y$ between the mean value of the most species rich polyculture $\bar{p}$ used in an experiment and the mean value of all the same species grown alone in monoculture $\bar{m}$, $\ln \left(y_{\bar{i}} / y_{i \bar{m}}\right)$. The second $\log$ ratio, which we will note as $\mathrm{LR}_{\text {max.min }}$, quantifies the proportional difference between the mean value of response variable $y$ in the most species rich polyculture to that of the taxon having the highest (lowest) value of $y$ in monoculture $\hat{m}$, as $\ln \left(y_{\bar{i}} / y_{i \hat{m}}\right)$ where $y_{i \hat{m}}$ is the value of the highest (lowest) monoculture when $\mathrm{LR}_{\text {net }}>0(<0)$. This response ratio tests whether a polyculture performs any differently than its single most efficient or productive species. When analyzing the distribution of log ratios among studies, we used mixed model ANOVAs that included experiment nested within study as random effects to account for variation in results among different researchers in different locations (since studies often report results of several independent experiments).

One benefit of $\log$ ratios is that they can be calculated for nearly every study. But the limitation is that they only compare the extreme values of diversity used in an experiment (mono- vs. most rich polyculture). As such, they quantify only the extreme cases of diversity loss while saying nothing about the nature of the diversity-function relationship between these extremes. To complement analyses of log response rations, we performed a second analysis that characterizes the form of diversity-function relationships. These analyses could only be run for studies that included three or more levels of richness in their design. For this subset, we fit data from individual experiments to several mathematical functions that have been used to describe diversity-function relationships previously (linear, exponential, log, power, and Michaelis-Menten functions). Residual maximum likelihood was used to generate best-fitting parameter estimates for each function. Because each function contains exactly two parameters, and because the fits of these curves were compared only within individual studies, the best-fitting function was deemed to be the one with the lowest residual sums of squares (i.e., highest $R^{2}$ ).

\section{REVIEW OF EXISTING EVIDENCE}

Question 1. Does producer diversity influence the efficiency and productivity of ecosystems?-Background-Perhaps the oldest hypothesis in BEF is that species diversity controls the efficiency by which communities capture limited resources and 
convert those into new biomass (Table $1, H l a-c$ ). Some of the earliest experiments to address this hypothesis (Naeem et al., 1994; Tilman and Downing, 1994) were criticized for manipulating diversity indirectly or for simulating nonrandom species loss in ways that might confound changes in richness with changes in the species composition of assemblages (Aarssen, 1997; Huston, 1997). Because of these criticisms, the design of most biodiversity experiments was altered so that researchers held the total initial seeding density or biomass of producers constant across several levels of richness, and then grew (1) all possible combinations of species at each level of richness or (2) species combinations selected at random from all possibilities. Thus, the most common hypothesis tested by these experiments was that, when averaged across all species and species combinations, the efficiency of resource use and producer biomass increases as a function of the initial number of species seeded or grown in an experimental unit.

Evidence-There is now a considerable amount of data that shows how the initial number of producer species in an experimental unit impacts the standing biomass of producers (Fig. 2A). In terrestrial ecosystems, these observations usually measure the amount of aboveground biomass, percentage cover, or occasionally plant density after a single growing season. In aquatic ecosystems, the response variable is typically chlorophyll $a$ or algal biovolume per volume water (planktonic microalgae), or biomass per area for sessile algae (as in the marine intertidal). Eighty-six percent of log response ratios summarizing the net diversity effect on producer biomass have been greater than zero (Fig. 2A). The mean value for $\mathrm{LR}_{\mathrm{net}}$ is $e^{0.36}$, indicating that the most diverse polycultures attain, on average, $1.43 \times$ more biomass than the average monoculture $(95 \%$ confidence interval $=1.36$ to $1.49 \times$, Table 2 ). These results are consistent for both aquatic and terrestrial systems with abundant data, suggesting considerable generality (Fig. 2B). Some important systems (e.g., wetlands and tropical and temperate forests) show more equivocal results, but these are also systems for which there is a relatively small amount of data.

At present, there are 59 observations from 17 experiments that describe how producer species richness impacts the concentrations of inorganic nutrients in soil or water (Fig. 2D). Log response ratios summarizing the net diversity effect on nutrient concentrations have been negative in 51 of 59 observations $(86 \%)$. The mean diversity effect size is $e^{-0.65}$, indicating that average nutrient concentrations in experimental units containing the most diverse polycultures are reduced by $48 \%$ relative to the mean monoculture value $(95 \%$ confidence interval $=27$ to $63 \%$, Table 2). Fifty-six of these 59 observations come from studies that have manipulated the richness of herbaceous plants in grasslands and examined the impact on concentrations of soil nitrate (Fig. 2E). Three observations come from studies performed using freshwater microalgae.

To date, we have found just seven observations in which a researcher has measured the direct impact of producer richness on rates of gross primary production or photosynthesis-either as the amount of $\mathrm{O}_{2}$ produced, or $\mathrm{CO}_{2}$ sequestered, per area or volume per time. All but one of these observations come from aquatic studies in which a researcher sealed micro- or macroalgae inside metabolism chambers and measured changes in the concentration of dissolved gases. The data are too scant to make many generalizations; however, it is worth noting that the net diversity effect on primary production is greater than zero for all seven estimates (Fig. 2G), with a $P$ value of 0.053 (Table 2 ). The most diverse polycultures produce (sequester) $\mathrm{O}_{2}\left(\mathrm{CO}_{2}\right)$ at a rate that is $e^{0.80}=2.22 \times$ faster than the mean monoculture (Table 2 ).

Conclusions - The balance of evidence provides overwhelming support for the hypothesis that producer species richness increases the efficiency by which plants and algae assimilate inorganic resources $(H 1 b$, Table 1$)$ and convert these into standing biomass (Hla, Table 1). Nearly all of our inferences about $H 1 b$ come from studies of grasslands plants, and as such, it is unclear whether these conclusions apply broadly across systems. In contrast, conclusions for Hla stem from nearly 500 experiments performed with several hundred types of plants and algae in numerous ecosystems. Though results are by no means universal, the level of generality in the direction and magnitude of diversity effects in the different systems is striking (Fig. 2B).

The fact that richness tends to increase producer biomass has been used to suggest that diversity loss will decrease the productivity of ecosystems (e.g., Tilman et al., 1996). These conclusions frequently come from grassland ecologists who measure annual accumulation of aboveground biomass and equate this to aboveground net primary production (ANPP) while ignoring belowground biomass and assuming that turnover of tissue through senescence and herbivory are negligible (Stocker et al., 1999; Niklaus et al., 2001). While equating peak aboveground biomass to ANPP may be reasonable in some cases, the underlying assumption of low tissue turnover needs validation. Similarly, there is a paucity of information about how producer richness impacts total NPP (above- plus belowground production) as well as how richness impacts rates of photosynthesis and gross primary production (GPP). Of the seven estimates available, data suggest that rates of total community photosynthesis are more rapid in diverse polycultures and that these increases are large in magnitude $(>2 \times$ the mean monoculture value). Nevertheless, the variance among estimates is large in spite of the fact that nearly all measurements come from a homogeneous set of algal systems (Fig. 2G, H). Given the lack of data, we believe that this is an area where more experimental effort is needed.

Fig. 2. Summary of log response ratios showing the impacts of producer diversity on five ecological properties. The left column of graphs shows the distribution of net diversity effects, $\mathrm{LR}_{\text {net }}$, which represent the proportional change in the response variables between the most diverse polycultures used in experiments and the average of the same species grown in monoculture. Each data point in a graph shows the diversity effect for one experiment, with experiments ranked along the $x$-axis from the largest to smallest effect size. The point of no diversity effect is shown as a dashed horizontal line in each graph. Solid horizontal lines give the $95 \%$ confidence intervals (CIs), estimated from mixed model ANOVAs that accounted for experiments nested within studies as a random effect. The middle column of graphs divides $L_{\text {net }}$ by the types of ecosystems that have been studied. Data points are the mean of all studies $\pm 95 \%$ CIs. The last column of graphs compares values of the response variables in the most diverse polyculture to those of the highest (for biomass) or lowest (for nutrient and litter concentrations) monoculture. For (C), we only used data where $L_{\text {net }}>0$ from (A) (i.e., experiments where diversity led to increased biomass). For (F) and (M), we only used data from (D) and (K) where $\mathrm{LR}_{\text {net }}<0$ (i.e., experiments where diversity decreased nutrient or litter concentrations). obs $=$ observed. 

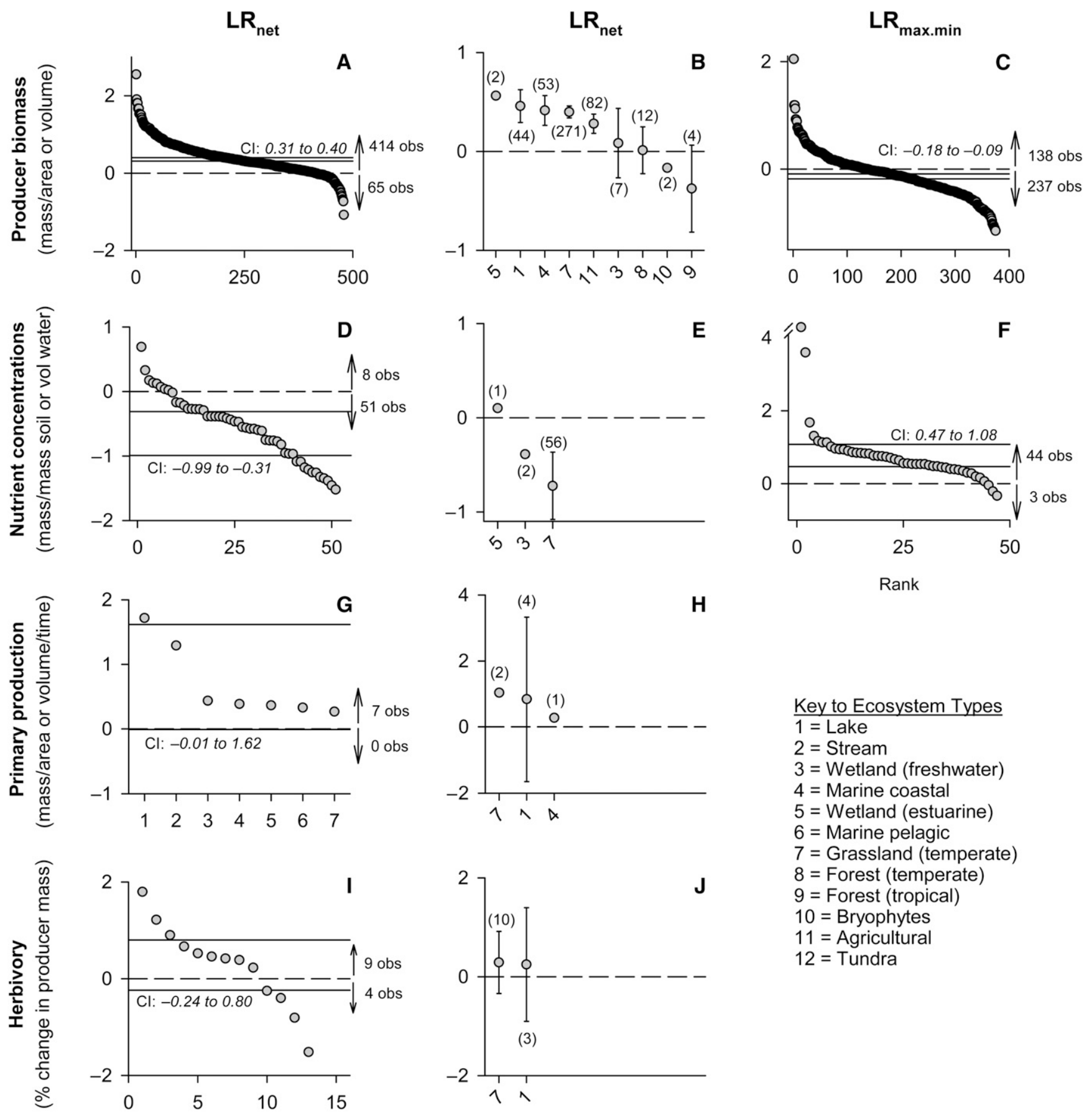

$$
\begin{aligned}
& \text { Key to Ecosystem Types } \\
& \hline 1=\text { Lake } \\
& 2=\text { Stream } \\
& 3=\text { Wetland (freshwater) } \\
& 4=\text { Marine coastal } \\
& 5=\text { Wetland (estuarine) } \\
& 6=\text { Marine pelagic } \\
& 7=\text { Grassland (temperate) } \\
& 8=\text { Forest (temperate) } \\
& 9=\text { Forest (tropical) } \\
& 10=\text { Bryophytes } \\
& 11=\text { Agricultural } \\
& 12=\text { Tundra }
\end{aligned}
$$

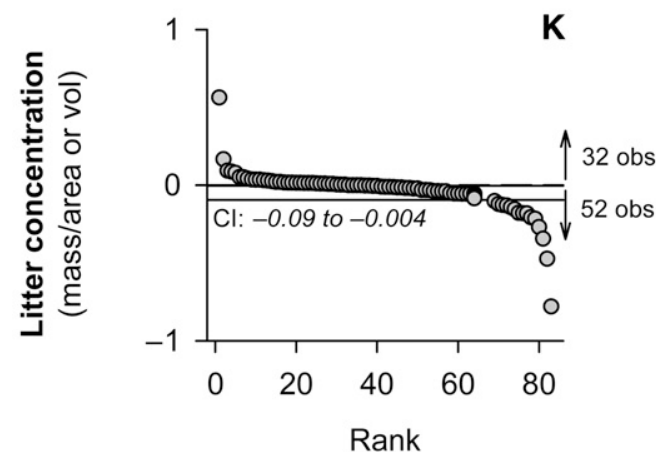

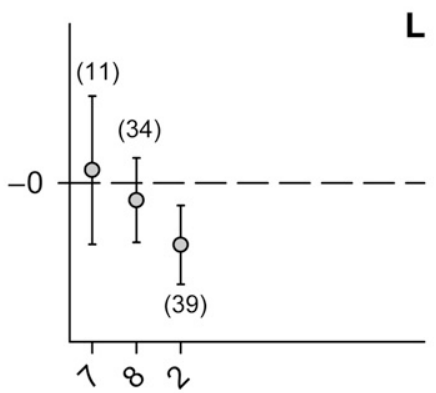

Ecosystem type

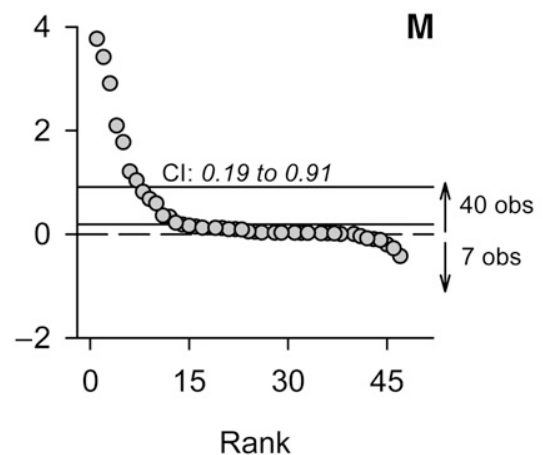


Question 2. Does producer diversity modify herbivory? -Background-Several subdisciplines in biology have a long-standing interest in how producer diversity influences losses of plant tissue to higher trophic levels. For example, in the agricultural sciences, a key goal of management is to minimize loss of production to herbivores. Andow (1991) summarized a large body of observational data from this field and found that plant polycultures tend to have a lower abundance of herbivorous pests, perhaps due to increased control of herbivores by natural enemies in plant polycultures. Hillebrand and Cardinale (2004) found a comparable relationship in natural aquatic ecosystems. These authors reviewed 172 observational studies that quantified the degree to which vertebrate and invertebrate herbivores reduced the biomass of algae and found that this impact declined as algal diversity increased. Edwards et al. (2010) similarly surveyed field experiments spanning a range in prey diversity and showed that diverse assemblages of sessile marine prey (including both algae and sessile invertebrates) were less impacted by consumers. Although the studies included in these reviews rarely manipulated species richness directly, the observations led authors to hypothesize that the amount of herbivory in ecosystems decreases as producer diversity increases $(H 2$, Table 1).

Evidence-To date, we have identified just 13 experimental observations of how producer richness modifies the impact of herbivores on producer biomass (Fig. 2I). Ten of the observations come from experiments performed with grassland plants, whereas three stem from studies of freshwater lake algae (Fig. $2 \mathrm{~J})$. All of the experiments manipulated richness in the presence/absence of herbivores and measured how producer diversity altered the loss of producer biomass. Log response ratios describing the net diversity effect were greater than zero for nine experiments and less than zero for four (Fig. 2I). The overall distribution of observations is not significantly different from zero $(P=0.27$, Table 2$)$.

Conclusions-At present, evaluation of the hypothesis that herbivore impacts on producer biomass decrease with increasing producer diversity (Table 1,H2) is hampered by the small number of experiments available. Of those that do exist, experiments do not show any consistent impact of producer diversity on how higher trophic levels impact the standing biomass of producers despite individual experiments noting significant effects (either positive or negative). However, our confidence in this conclusion is low, and the "bottom-up" impact of producer diversity on higher trophic levels is a topic in need of more targeted research.

Question 3. Does producer diversity influence the decomposition of litter? - Background-As biodiversity experiments established that producer diversity leads to greater biomass, attention turned toward understanding the ultimate fate of the extra carbon (Hattenschwiler et al., 2005; Srivastava et al., 2009). Once producer biomass is formed, it can either be consumed by herbivores (see Question 2) or die. After death, the organic litter can either be decomposed with the elements recycled back into their inorganic forms, or the recalcitrant portion can be incorporated into organic matter and stored over longer periods. Understanding how producer richness affects the amount of material that gets stored vs. recycled is critical given the central role that producers play in the global $\mathrm{C}$-cycle, including the potential for sequestering anthropogenic $\mathrm{CO}_{2}$.
Evidence-At present, there are 84 observations that describe how producer diversity impacts standing concentrations of producer litter after some period of decomposition (the mean duration of decomposition experiments has been 180-d). The distribution of log response ratios for the net diversity effect, $\mathrm{LR}_{\text {net }}$, is significantly less than zero (Table 2) with $62 \%$ of all observations being negative (Fig. 2K). Litter in the most diverse producer polycultures has, on average, $e^{-0.05}=0.95 \times$ the standing litter mass of the average monoculture (Table 2, 95\% $\mathrm{CI}=0.91$ to $0.996 \times)$. Most experiments have been performed in streams (Fig. 2L) where researchers have examined how bacteria, fungi, and/or invertebrate shredders reduce the mass of terrestrial leaf litter placed in litter bags. Although comparable studies have been performed in forests and grasslands, streams are the only system that shows a significant negative distribution of effect sizes (Fig. 2L).

Conclusions - The balance of evidence is consistent with the hypothesis that producer diversity leads to more decomposition and lower standing stocks of detritus (Table 1, H3). This conclusion contrasts with that of Srivastava et al. (2009) who analyzed a much smaller data set than is available now and found no impact of litter diversity on decomposition. Even so, we found little consistency in results across ecosystems, as studies performed in streams are the only ones to show a diversity effect that differs from zero (Fig. 2L). High variation in $\mathrm{LR}_{\text {net }}$ from terrestrial studies could indicate that the composition of litter mixtures has more influence on decomposition than richness of litter types, as has been proposed by others (Gartner and Cardon, 2004). Furthermore, although diversity effects on detrital stocks are significantly different from zero, they are small. The average experiment included in these analyses lasted $180 \mathrm{~d}$ and, during this time, litter in polycultures lost just $5 \%$ more mass than the average monoculture. Compared to the impacts of producer diversity on the utilization of inorganic resources and biomass production, the "after-life" effects of plant diversity on decomposition are minor.

Question 4. What mechanisms are responsible for diversity effects on ecosystem processes?-Background-Darwin proposed more than a century ago that biodiversity might control the productivity of ecosystems due to the division of labor among species. The idea that each species is unique in how it uses its environment ultimately formed the foundation for the modern niche concept (Grinnell, 1917; Hutchinson, 1967). Throughout most of the 20th century, the niche concept was primarily developed to explain what ecological factors maintain biological diversity in the face of competition among species for scarce resources (Chase and Leibold, 2003). But in the late 20th century, it was proposed that whenever species coexist by niche differences, a diverse community should capture a greater fraction of limiting resources and, in turn, produce more biomass (Tilman et al., 1997; Tilman, 1999). Because of the simplicity and intuitive appeal of this hypothesis, many researchers assumed that diversity effects observed in early BEF experiments were likely explained by some form of niche or resource partitioning among species.

However, Aarssen (1997) and Huston (1997) proposed an alternative explanation. These authors separately argued that diversity effects on producer biomass were more likely driven by the presence of highly productive species that dominate processes in diverse communities. Huston named this the selection 
TABLE 2. Results of mixed model ANOVAs used to test whether the distribution of diversity effect sizes on various ecological properties differ from zero. Effect sizes were summarized using two log response ratios. LR $_{\text {net }}$ gives the net diversity effect comparing the proportional difference between the response variable measured in the most diverse polyculture of an experiment to the average of all monocultures. $\mathrm{LR}_{\max \text { min }}$ compares values in the most diverse polyculture to values in the highest (if $\mathrm{LR}_{\text {net }}>0$ ) or lowest monoculture (if $\mathrm{LR}_{\mathrm{net}}<0$ ). All models included experiments nested within studies as random effects, since papers often reported the results of multiple independent experiments.

\begin{tabular}{|c|c|c|c|c|c|c|}
\hline Model and variables & Estimate & SE & df & $t$-value & $\operatorname{Pr}>|t|$ & Figure \\
\hline \multicolumn{7}{|c|}{$L R_{\text {net }}=$ Most diverse polyculture $v$ s. mean of all monocultures... } \\
\hline $\begin{array}{l}\text { Producer biomass } \\
\text { Nutrient concentrations } \\
\text { Primary production } \\
\text { Loss of plant mass to herbivores } \\
\text { Litter concentrations }\end{array}$ & $\begin{array}{r}0.36 \\
-0.65 \\
0.80 \\
0.28 \\
-0.05\end{array}$ & $\begin{array}{l}0.02 \\
0.16 \\
0.29 \\
0.24 \\
0.02\end{array}$ & $\begin{array}{c}313 \\
11.3 \\
4 \\
12 \\
44.9\end{array}$ & $\begin{array}{r}14.96 \\
-4.20 \\
2.73 \\
1.16 \\
-2.2\end{array}$ & $\begin{array}{c}<0.01 \\
<0.01 \\
0.053 \\
0.27 \\
0.03\end{array}$ & $\begin{array}{l}2 \mathrm{~A} \\
2 \mathrm{D} \\
2 \mathrm{G} \\
2 \mathrm{I} \\
2 \mathrm{~K}\end{array}$ \\
\hline \multicolumn{7}{|c|}{$L R_{\max . \min }=$ Most diverse polyculture vs. value of the most extreme monoculture... } \\
\hline
\end{tabular}

probability effect, whereby the probability of including ("selecting") any particular species in an experimental community increases as a function of species richness. While Huston viewed the selection probability effect as a statistical artifact of experiments, it has since been shown that a simple correlation between species richness and the probability of including any single species in a community cannot, by itself, generate an effect of diversity on ecological processes (Cardinale et al., 2004; Weis et al., 2007). Rather, for any single-species to drive a diversity effect, that species must alter the relative yields or per capita performance of other species through some real biological interaction like competition (Loreau and Hector, 2001). Even so, Huston's paper stimulated an important debate about the extent to which diversity effects are driven by the contributions of individual species to ecosystem processes, or by diversity per se.

In an attempt to resolve this debate, researchers have developed a variety of statistical tests intended to separate the effects of species richness from species "composition." These tests range from (1) simple ANOVAs that assess the significance of composition and richness after accounting for the other (usually by nesting composition within levels of richness), to (2) statistics that compare the observed yields of polycultures to their expected values from growth in monocultures (see Hector [1998] and Loreau [1998] for summaries), to (3) methods referred to as additive partitioning (Loreau and Hector, 2001; Fox, 2005) that use calculations similar to the Price equation from evolutionary genetics to determine how much of a diversity effect is driven by a single species (referred to as selection effects) vs. the residual that is driven by multiple species (what the original authors called complementarity effects).

In the papers comprising our data set, claims of complementarity or selection effects dominate the literature. Specific mechanisms like interspecific facilitation, niche or resource partitioning, or various forms of intra- and interspecific competition are cited only occasionally (Fig. 3A). Of the papers that have claimed a mechanism in their abstract or discussion, only 47\% present any direct statistical test to evaluate the claim (Fig. 3B). Of the remaining studies that present no direct test, $25 \%$ provide ancillary support for their claimed mechanism (e.g., supplemental experiments), while $25 \%$ had no data for any type of mechanistic test. The remaining 50\% had the relevant data needed to test the claimed mechanism, but did not perform a test. For studies of primary producers, claims about mecha- nisms backed by a direct test are dominated by the Loreau and Hector (2001) method of additive partitioning. In the context of the additive partitioning equation, selection and complementarity effects are statistically defined processes rather than mechanisms per se; estimated values of these metrics do not correlate directly with ecological mechanisms like resource partitioning, facilitation, or competitive exclusion (more on this below). Nevertheless, we summarize those results here.

Evidence-Because complementarity and selection effects are measured in real units, we divide our analyses into aquatic (mass per volume) and terrestrial ecosystems (mass per area). In aquatic systems, the $95 \%$ confidence interval for complementarity effects ranges from 0.02 to $0.77 \mathrm{~g}$ biomass $\cdot \mathrm{L}^{-1}$ with $81 \%$ of all observations being greater than zero (Fig. $3 \mathrm{C}$ ). In terrestrial ecosystems, the confidence interval ranges from 41 to $110 \mathrm{~g}$ biomass $\cdot \mathrm{m}^{-2}$, with $80 \%$ of observations being greater than zero (Fig. 3F). In aquatic ecosystems, selection effects do not differ from zero, with a nearly equal number of studies having estimates of selection greater than vs. less than zero (Fig. 3D). In terrestrial systems, selection effects were significantly greater than zero with a confidence interval of 46 to $104 \mathrm{~g}$ biomass $\mathrm{m}^{-2}$ (Fig. 3G).

There has been some speculation in the literature about how complementarity and selection effects covary. The relationship between these two variables is potentially useful because it can show whether individual species tend to enhance the effects of complementarity on production (a positive correlation). Alternatively, it can show whether single species tend to negate the impacts of complementarity (a negative correlation), which might occur if the dominant competitor is also the least productive species. In aquatic ecosystems, we found a strong negative correlation between the magnitude of complementarity and selection effects $(r=-0.94, P<0.01$, Fig. 3E); but this was driven by four observations that were $>2$ standard deviations lower than the means. When these observations were removed, there was no correlation between effects $(r=0.05, P=0.74)$. A $\chi^{2}$ contingency analysis indicated that the number of observations within each combination of positive and negative complementarity $\times$ selection effects (dashed lines in Fig. 3E indicate the four combinations with $n$ number of observations in each) did not differ from chance $\left(\chi^{2}=0.94, P=0.33\right)$. In terrestrial systems, there was a significant but weak negative correlation between complementarity and selection effects $(r=-0.27$, 


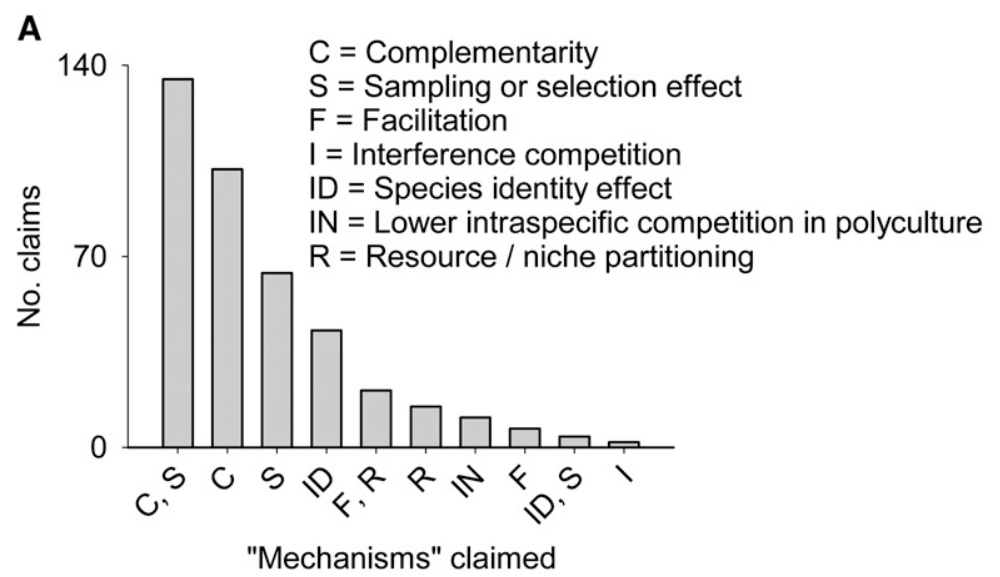

C
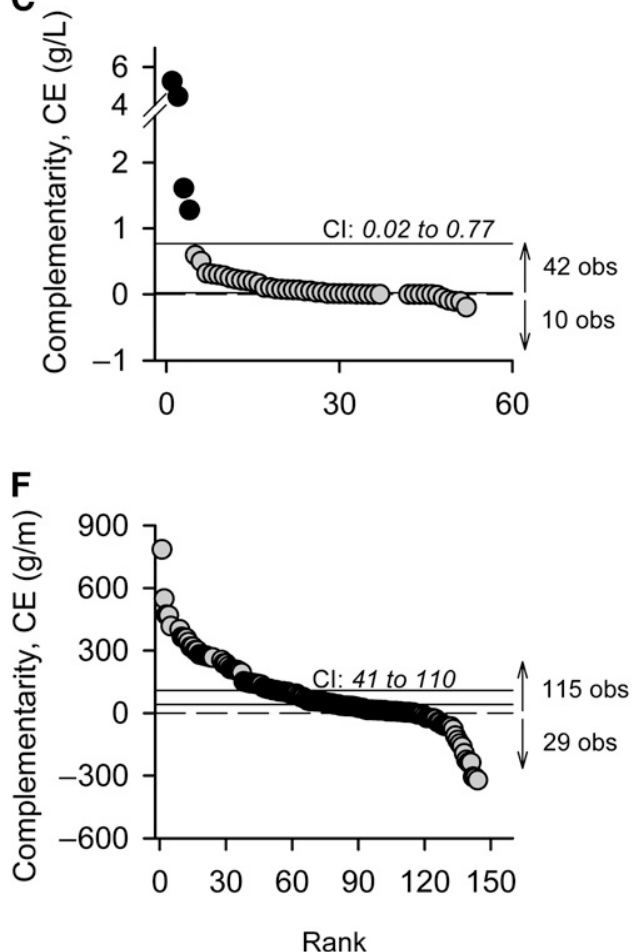

D

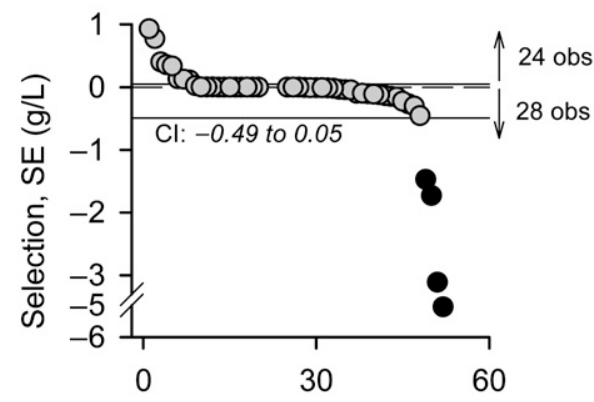

G

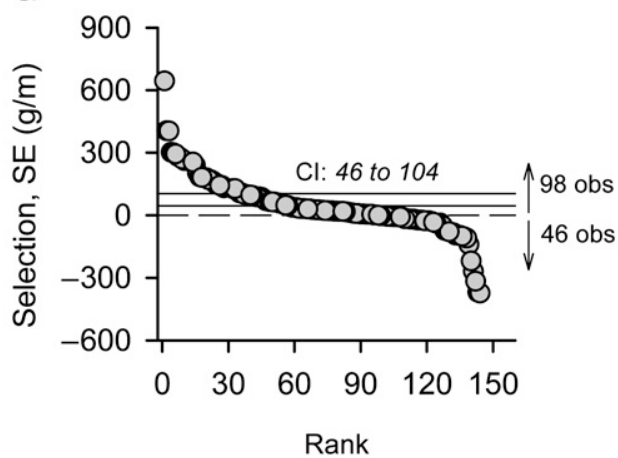

B

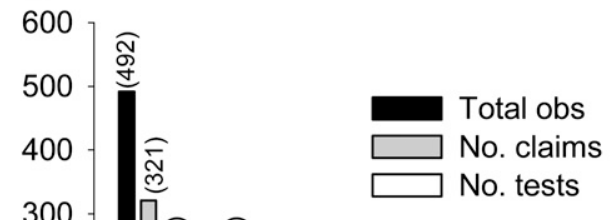

Fig. 3. A summary of diversity-function mechanisms reported in the papers we reviewed. We kept track of "mechanisms" that were claimed to underlie diversity effects in the abstracts or discussions of each paper. At least nine mechanisms or combinations of mechanisms were cited (tallied in panel A). Of these citations, panel B shows the number of times a paper presented any direct statistical test of the claimed mechanism. For example, of the 492 experiments that examined how producer richness impacts producer biomass, 321 claimed evidence of a particular mechanism in their abstract or discussion, but only 198 presented any direct statistical test to back up those claims. Because tests of complementarity effects (CE) and selection effects (SE) dominated the literature, we summarize these effects for aquatic (panels C-E) and terrestrial (panels F-H) ecosystems. Each point in a graph represents estimates from one experiment, and values have been ranked along the $x$-axis from highest to lowest. Large statistical outliers are shown as black dots (see main text for explanation). The 95\% confidence intervals from a mixed model ANOVA are given as the solid horizontal lines; zero is noted as the horizontal dashed line. Panels $\mathrm{E}$ and $\mathrm{H}$ show the relationship between the magnitude of CE and SE. In panel E, four statistical outliers are shown in black. Graphs have been divided into four regions that give all combinations of the two effect types (+CE/+SE, +CE/-SE, -CE/+SE, and -CE/-SE). The number of observations in each region is shown, as well as the percent deviation from a $\chi^{2}$ contingency test for independence.

$P<0.01$, Fig. 3H). This led to a nonrandom association in the direction of effect sizes $\left(\chi^{2}=9.09, P<0.01\right)$; measures with positive complementarity and negative selection occurred more often than by chance, whereas positive selection and negative complementarity also occurred more often than by chance (Fig. 3H).
Conclusions - When it comes to the mechanisms behind biodiversity effects, the BEF literature is a "reader beware" field. Less than half of all claims made in the abstracts or discussions of papers are backed by any direct statistical test. Just over half of the papers that claim a mechanism make any attempt at verification, leaving a large fraction of claims unsubstantiated. 
These trends suggest that reviewers and editors need to encourage authors to better support their claims in future papers, and authors need to limit their speculation about BEF mechanisms.

Of the tests that have been performed, diversity effects in aquatic ecosystems are driven by some form of complementarity among species with no consistent contribution by speciesspecific selection effects. This is not to say that individual species have not driven variation in producer biomass-rather, the most influential species in polyculture is equally likely to have the highest or lowest biomass in monoculture, which causes the average selection effect to be no different from zero. In contrast, diversity effects in terrestrial ecosystems appear to be driven equally by selection effects and complementarity. The confidence intervals for these two measures were nearly equal, suggesting comparable average contributions by singlespecies and multispecies processes. We found no evidence of an association between complementarity and selection effects in aquatic ecosystems. There was, however, a weak negative correlation between complementarity and selection effects in terrestrial ecosystems. As a result, there is limited evidence that positive complementarity effects are sometimes offset by negative selection effects (Jiang et al., 2008; Boyer et al., 2009). At the same time, it is equally likely for positive values of selection effects to be cancelled by negative complementarity effects (Fig. 3H).

In spite of widespread claims about the role of niche partitioning in driving BEF relationships, researchers have rarely provided any direct evidence that niche partitioning is responsible for higher productivity in mixtures. Many claims about niche partitioning come from qualitative interpretations of species natural histories or differences in functional traits, which are always subject to alternative explanations. Others have interpreted positive values of the complementarity effect as evidence for niche partitioning, but this is not correct. Several authors have now pointed out complementarity effects, as they are calculated in the equations for additive partitioning, represent the net balance of all biological processes that influence biomass - both positive and negative-that involve two or more species (Petchey, 2003; Hooper and Dukes, 2004; Cardinale et al., 2007). In the absence of additional information, complementarity effects cannot be equated with any biological mechanism or species interaction.

We believe it is important that BEF studies now move beyond qualitative reasoning and post hoc statistical attempts to interpret mechanisms. To do so, experiments need to directly test the mechanisms they have hypothesized are operating to produce greater biomass at higher species richness. When species have unique resource needs, a considerable body of theory predicts that species growth rates will exhibit negative frequency dependence, where individuals have a per capita growth advantage when rare (reviewed by Chesson, 2000). A per capita growth advantage occurs because intraspecific interaction strengths are greater than interspecific interactions, which can be detected through direct measures of interaction strength, measures of frequency dependence in per capita growth rates, or in the mutual ability of species to invade established communities (i.e., growth rates when rare). These measures have been used to demonstrate niche-based coexistence in plants (Levine and HilleRisLambers, 2009) and to explain resource partitioning among predators (Northfield et al., 2010) and have been mathematically linked to measures of relative yield that are widely used in agriculture (Carroll et al., in press). Thus, all the tools are in place to detect niche partitioning if it is, in fact, responsible for the effects of producer richness on resource capture and biomass.

Question 5. Do diverse communities "out perform" their most efficient or productive species?-Background-Many natural resource managers are unlikely to be interested in "net" diversity effects. Instead, they want to know whether a diverse community is more efficient or productive than the single "best" species that could be grown or conserved (e.g., the species that produces the largest crop or most wood or the one that most efficiently removes nutrient wastes from water). When a polyculture yields more mass than even its highest yielding species, researchers in the plant sciences call this transgressive overyielding (Vandermeer, 1989). Ecologists have tested for analogs of transgressive overyielding in several ecological functions by asking whether polycultures perform processes any differently from their most efficient or productive species (H5a-c, Table 1). Transgressive overyielding and its analogues are often viewed as unequivocal evidence that diversity per se is needed to maximize an ecological function (Loreau, 1998).

Evidence-To test for transgressive overyielding, we took the subset of studies from Fig. $2 \mathrm{~A}$ where $\mathrm{LR}_{\text {net }}>0$ (i.e., those that showed a positive net diversity effect on producer biomass) and calculated a second log response ratio that compares the biomass produced in the most diverse plant polycultures to that of the highest yielding species in monoculture. Of the 375 resulting observations, $\mathrm{LR}_{\text {max.min }}$ was greater than zero in just 138 - meaning, there was evidence of transgressive overyielding in just $37 \%$ of all observations (Fig. 2C). The remaining $63 \%$ of observations suggest that diverse polycultures yield less biomass than the single highest yielding monoculture. The overall distribution of values for $L_{\text {max.min }}$ was significantly negative with a mean value of $e^{-0.14}$ (Table 2), which means that producer yield in the most diverse polyculture was, on average, just $0.87 \times$ that of the highest yielding monoculture.

We also tested whether diverse polycultures reduced nutrient concentrations to a lower level than is achieved by the most efficient monoculture. Using the subset of studies from Fig. 2D where $\mathrm{LR}_{\text {net }}<0$ (i.e., those where diversity reduced nutrient concentrations in soil or water), we found that 44 of 47 observations were greater than zero, and the distribution of values for $\mathrm{LR}_{\text {max.min }}$ was significantly greater than zero (Table 2). These results indicate that standing nutrient concentrations in soil or water were higher, rather than lower, in producer polycultures compared to the monoculture that reduces nutrients down to their lowest levels (Fig. 2F).

Last, we tested whether diverse polycultures tend to have lower litter concentrations than the monoculture with the lowest amount of detritus (i.e., experiments in Fig. $2 \mathrm{~K}$ where $\mathrm{LR}_{\text {net }}$ $<0)$. The distribution of values for $\mathrm{LR}_{\max \text { min }}$ was significantly greater than zero (Table 2), indicating that litter concentrations tend to be higher in producer polycultures compared to the monoculture that has the lowest litter concentration (Fig. 2M).

Conclusions-There is presently little evidence to support the hypothesis that diverse polycultures out-perform their most efficient or productive species (H5a-c, Table 1). Although $37 \%$ of observations for producer biomass are consistent with the concept of transgressive overyielding, it is almost twice as common for diverse polycultures to produce less biomass than the highest yielding monoculture. Such findings corroborate an early review of data in the agronomy literature (Trenbath, 1974), 
as well as earlier meta-analyses that have found little evidence of transgressive over-yielding in studies of grassland plants (Cardinale et al., 2006, 2007; Cadotte et al., 2008). Similar to results for producer biomass, we found no evidence that diverse polycultures reduce nutrient or litter concentrations to levels that are lower than the lowest monoculture. On the contrary, polycultures have higher nutrient and litter concentrations than the most extreme monoculture. Thus, when comparing ecological properties measured in the most diverse polycultures used in experiments to properties measured in monocultures, diversityfunction relationships look like those in Fig. 4. On average, producer biomass increases with increasing richness, but polycultures usually attain less biomass than the highest yielding species (Fig. 4A). The concentrations of nutrients and litter in soil or water both decrease with increasing richness, but concentrations are higher than what is achieved by the most efficient monoculture (Fig. 4B).

Question 6. What is the shape of the diversity-function relationship?-Background-Much early work in the field of BEF research was stimulated by a seminal book by Ehrlich and Ehrlich (1981) that compared biodiversity to the rivets on an airplane wing. These authors argued that wings contain many redundant rivets such that a certain number of rivets could pop out or fail before the airplane wing becomes compromised, but there is a point where loss of one too many rivets leads to catastrophic consequences for passengers on the plane. By analogy, they argued that nature contains many species that are redundant in the functions they perform; but loss of one too many species could have catastrophic consequences for the services that ecosystems provide to humanity.

Beyond the overly dramatic analogy, the "rivet-redundancy" hypothesis makes a testable prediction that the relationship between biodiversity and ecosystem processes should be positive, but decelerating. Initial loss of species should have minimal impacts on a process, whereas larger losses of diversity have accelerating impacts (Fig. 5). In addition to this hypothetical relationship, many other functional forms have been proposed for BEF relationships (see figures in Naeem, 1998; or Schlapfer et al., 1999 for summaries). Here we distil these additional hy- potheses into just two (Fig. 5) - ecological functions decline linearly with loss of species (the proportional loss hypothesis), or functions decline exponentially with loss of diversity (what we call the immediate catastrophe hypothesis). With the data now in hand, it is possible to ask which of these hypotheses is best supported by existing studies.

Evidence-For this analysis, we focused on studies that have examined how producer diversity impacts producer biomass, nutrient concentrations, and litter concentrations, because these were the three ecosystems properties with a consistent response to producer diversity (Fig. 2A, D, K). We used only the subset of data that is consistent with the general direction of diversity effects $\left(L^{n e t}>0\right.$ for producer biomass $L_{n} R_{\text {net }}>0$ for nutrient and litter concentrations, see Fig. 2), which eliminates difficulties of interpreting coefficients for both positive and negative curves.

For any experiment that manipulated four or more levels of richness, the measured response variable was fit to five mathematical functions using maximum likelihood (linear, exponential, log, power, and the Michaelis-Menten [M-M] version of a hyperbolic). Log, power, and M-M functions are all positive and decelerating, but only the M-M contains a saturating asymptote. To facilitate comparisons, we made two data transformations: (1) all values were standardized by the mean monoculture value so that curves represent proportional changes in the response variables across levels of richness, and (2) nutrient and litter concentrations were transformed by their inverse so that loss of richness corresponds to a reduction in nutrient uptake (as opposed to an increase in standing nutrient concentrations) and a reduction in decomposition (as opposed to an increase in litter concentrations).

Of the studies that have shown a positive effect of producer diversity on producer biomass, $79 \%$ were best fit by some form of a positive but decelerating curve (log, power, or M-M functions, Fig. 5A). Of these relationships, the M-M function was the best fit in $53 \%$ of experiments, explaining an average $73 \%$ of variation (Table 3). Coefficients for the M-M function suggest that, on average, producer biomass saturates at $2.38 \times$ the mean monoculture biomass, and it takes 1.35 species to attain
A

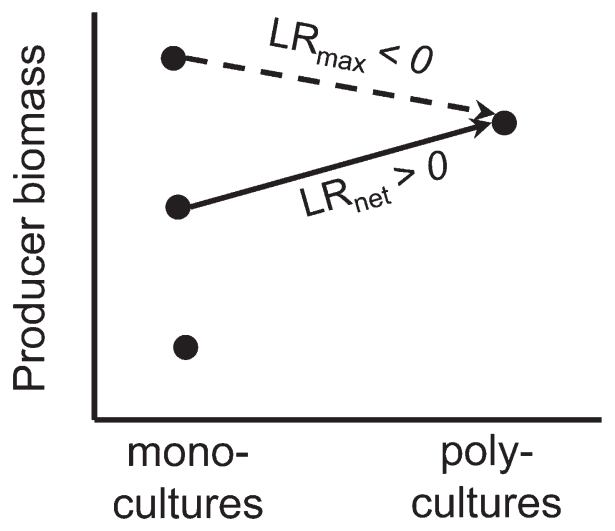

B

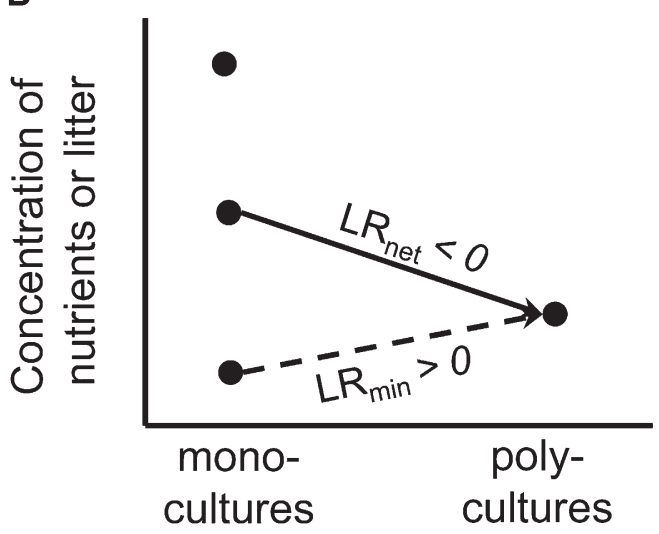

Fig. 4. A graphical summary of our statistical tests that rely on log response ratios to summarize the diversity-function relationship. When comparing functions measured in the most diverse polycultures to functions measured in monocultures, producer biomass increases with increasing richness, on average (solid line, panel A). But polycultures attain less biomass than the highest yielding species (dashed line). The concentrations of nutrients and litter in soil or water both decrease with increasing richness, on average (solid line, panel B). But concentrations are higher than what is achieved by the most efficient monoculture (dashed line). 

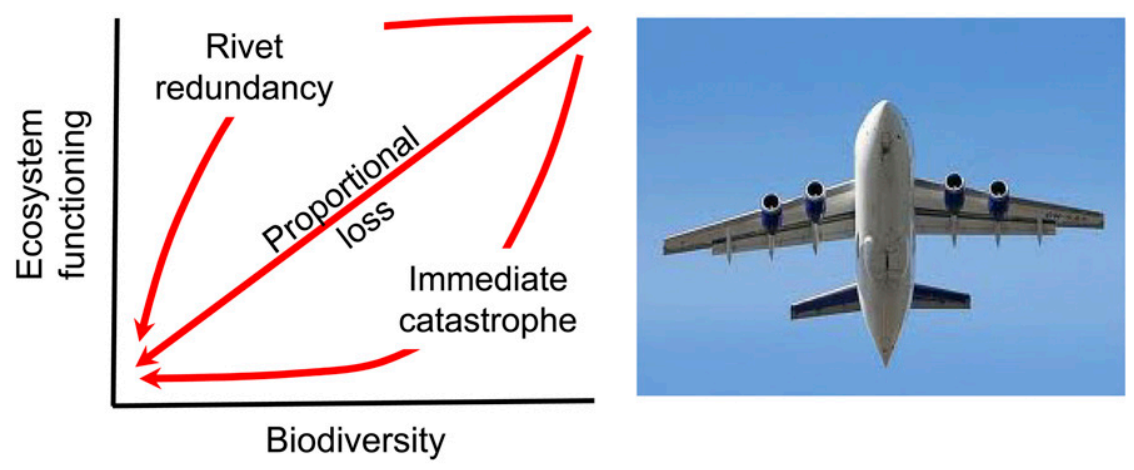

Biodiversity
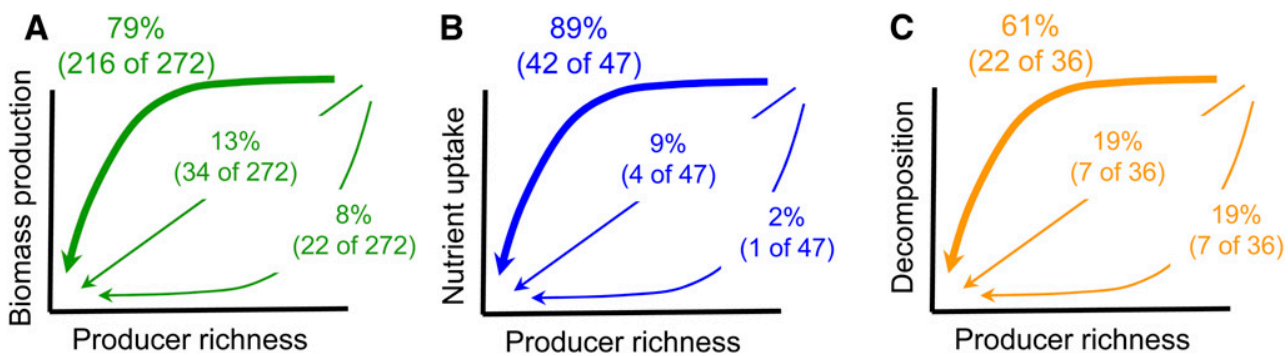

Fig. 5. Summary of the form of diversity-function relationships. Most predictions about the ecological consequences of diversity loss can be distilled into three general hypotheses (main panel, top): (1) Erhlich and Erhlich's (1981) rivet-redundancy hypothesis predicts that initial losses of diversity will be accompanied by minimal change in the functioning of ecosystems because, much like the redundancy built into rivets on an airplane wing, some fraction of species are redundant in the processes they perform in nature. However, at some point, loss of species lead to rapid declines in ecological function, much like the loss of one too many rivets can lead to failure of an airplane wing. (2) Others have proposed that the functioning of ecosystems declines proportional to species loss, still others have argued that (3) even minimal species loss leads to an immediate catastrophe and large declines in the functioning of ecosystems. We put these three hypotheses to the test by fitting five mathematical functions (linear, exponential, log, power, and Michaelis-Menten) to data from studies that have manipulated species richness and measured producer biomass, nutrient uptake, or decomposition at three or more levels of richness. The number and percentage of studies best explained by the three hypotheses are shown in panels A-C. Corresponding information on statistical fits and parameter values for each function are given in Table 3.

half of this asymptotic maximum value. Results were similar for the relationship between producer richness and nutrient uptake where a positive but decelerating relationship was the best fit to data in $89 \%$ of experiments (Fig. 5B). The M-M function was the single best fitting function in $51 \%$ of experiments, explaining an average $72 \%$ of all variation (Table 3). Parameter values suggest that the most diverse producer assemblage sequesters $5 \times$ more nutrients than the mean monoculture, and it takes two species to attain half of this maximum value.

Although decelerating functions were still the predominant fit to estimates of decomposition, it is noteworthy that linear and exponential relationships were the best fit in a combined 38\% of all experiments (Fig. 5C). It is also noteworthy that all of the functions explained an average $30 \%$ or less of the variation in an experiment, suggesting that none of the relationships were a particularly good fit to the decomposition data (Table 3).

Conclusions - The balance of evidence shows a positive but decelerating relationship between species richness and ecosystem processes, similar to that predicted by the rivet-redundancy hypothesis. With the possible exception of decomposition, there is minimal evidence that processes decrease linearly or exponentially with species loss. Of the decelerating functions tested, the M-M function was the best fit in most cases. This is noteworthy because the M-M function is the only function that predicts a truly saturating curve, rather than just a decelerating relationship. But contrary to the name of Ehrlich and Ehrlich's rivet-redundancy hypothesis, evidence of a saturating curve is not evidence that species are actually redundant in the functions they perform. Even niche models that specifically assume every species uses resources in a unique way produce the same saturating relationship (Tilman et al., 1997; Cardinale et al., 2004), as this is an inevitable consequence of packing species into any system with finite resources (Cardinale et al., 2009b). Nevertheless, the satisfactory fit of data to a saturating model does suggest that some fraction of species can be lost with minimal change to ecological processes and that beyond a certain level of species loss, significant changes in ecological processes occur. The M-M function also allows us to put bounds on the maximum function that could be achieved by a community and to define the levels of diversity that may be needed to achieve different management objectives. These abilities lead to our next question:

Question 7. What fraction of species do we need to maintain ecosystem processes? - Background - In 1999, Schlapfer et al. (1999) surveyed experts and asked their opinions on how many species are required to maintain ecosystem functioning. Experts predicted that $50 \%$ of species were required to maintain ecosystem processes within $75 \%$ of their natural state $(H 7$, Table 1$)$. While expert opinions may be useful in the absence of data, there is now a large number of experiments that can be used to calculate these estimates directly. We have already shown that the M-M function is a good fit to data from the majority of experiments (Table 3). If we transform the $x$-axis of all experiments such that richness is expressed on a proportional scale, $S_{i} / S_{\max }$, where $S_{\max }$ is the highest number of species used, then 
TABLE 3. A comparison of the fit of different functions (linear, exponential, log, power, and Michaelis-Menten) describing the relationship between algal species richness $S$ and each of three response variables.

\begin{tabular}{|c|c|c|c|c|}
\hline Response variable & Number best fit (\%) & Mean $R^{2}$ & Mean value of $a(\mathrm{SD})$ & Mean value of $b(\mathrm{SD})$ \\
\hline \multicolumn{5}{|l|}{ 1. Producer biomass a } \\
\hline Linear, $\left(Y_{\mathrm{P}} / Y_{1}\right)=a+b \times S$ & $34(13)$ & 62 & $1.03(0.29)$ & $0.11(0.21)$ \\
\hline Exponential, $\ln \left(Y_{\mathrm{P}} / Y_{1}\right)=a+b \times S$ & $22(8)$ & 60 & $0.05(0.18)$ & $0.06(0.12)$ \\
\hline $\log ,\left(Y_{\mathrm{P}} / Y_{1}\right)=a+b \times \ln (S)$ & $35(13)$ & 70 & $1.01(0.14)$ & $0.40(0.57)$ \\
\hline Power, $\ln \left(Y_{\mathrm{P}} / Y_{1}\right)=a+b \times \ln (S)$ & $38(14)$ & 71 & $0.03(0.10)$ & $0.22(0.27)$ \\
\hline Michaelis-Menten, $\left(Y_{\mathrm{P}} / Y_{1}\right)=a \times S /(b+S)$ & $143(53)$ & 73 & $2.38(3.89)$ & $1.35(2.49)$ \\
\hline \multicolumn{5}{|l|}{ 2. Nutrient uptake (for $\mathrm{LR}_{\text {net }}<0$ ) ${ }^{\mathrm{b}}$} \\
\hline Linear, $\left(Y_{\mathrm{P}} / Y_{1}\right)^{-1}=a+b \times S$ & $4(9)$ & 54 & $3.13(10.12)$ & $0.24(0.50)$ \\
\hline Exponential, $\ln \left(\left[Y_{\mathrm{P}} / Y_{1}\right]^{-1}\right)=a+b \times S$ & $1(2)$ & 53 & $0.26(0.40)$ & $0.06(0.05)$ \\
\hline $\log ,\left(Y_{\mathrm{P}} / Y_{1}\right)^{-1}=a+b \times \ln (S)$ & $3(6)$ & 67 & $1.62(3.45)$ & $2.06(6.27)$ \\
\hline Power, $\ln \left(\left[\mathrm{Y}_{\mathrm{P}} / \mathrm{Y}_{1}\right]^{-1}\right)=a+b \times \ln (S)$ & $15(32)$ & 71 & $0.08(0.22)$ & $0.37(0.31)$ \\
\hline Michaelis-Menten, $\left(Y_{\mathrm{P}} / Y_{1}\right)^{-1}=a \times S /(b+S)$ & $24(51)$ & 72 & $4.99(11.47)$ & $2.03(4.63)$ \\
\hline \multicolumn{5}{|l|}{ 3. Decomposition ${ }^{c}$} \\
\hline Linear, $\left(Y_{\mathrm{P}} / Y_{1}\right)^{-1}=a+b \times S$ & $7(19)$ & 30 & $0.96(0.24)$ & $0.06(0.17)$ \\
\hline Exponential, $\ln \left(\left[Y_{\mathrm{P}} / Y_{1}\right]^{-1}\right)=a+b \times S$ & $7(19)$ & 30 & $-0.03(0.14)$ & $0.04(0.14)$ \\
\hline $\log ,\left(Y_{\mathrm{P}} / Y_{1}\right)^{-1}=a+b \times \ln (S)$ & $1(3)$ & 30 & $1.00(0.10)$ & $0.14(0.34)$ \\
\hline Power, $\ln \left[\left(Y_{\mathrm{P}} / Y_{1}\right)^{-1}\right]=a+b \times \ln (S)$ & $6(17)$ & 30 & $0.00(0.07)$ & $0.10(0.18)$ \\
\hline Michaelis-Menten, $\left(Y_{\mathrm{P}} / Y_{1}\right)^{-1}=a \times S /(b+S)$ & $15(42)$ & 29 & $1.19(0.30)$ & $0.18(0.23)$ \\
\hline
\end{tabular}

${ }^{\text {a }} Y_{\mathrm{P}}=$ mean biomass (mass.area ${ }^{-1}$ or $\left.\mathrm{vol}^{-1}\right)$ in polyculture $\left(\geq 3\right.$ levels of $S$ ) vs. $Y_{1}=$ mean of all monocultures

b $Y_{\mathrm{P}}=$ mean nutrient concentration (mass $\cdot$ area $^{-1}$ or vol $^{-1}$ ) in a polyculture $\left(\geq 3\right.$ levels of $S$ ), $Y_{1}=$ mean concentration of all monocultures.

${ }^{\mathrm{c}} Y_{\mathrm{P}}=$ mean mass of detritus in polyculture ( $\geq 3$ levels of $\left.\mathrm{S}\right), Y_{1}=$ mean of all monocultures.

changes in richness are standardized such that all studies range between $S_{1} / S_{\max }$ and 1 . The M-M function can then be rearranged to

$$
\frac{S}{S_{\max }}=\frac{\theta a b}{a-\theta a}
$$

(see Appendix 1). Using parameter values for $a$ and $b$ that we have already estimated from experiments (Table 3), Eq. 1 can be used to directly calculate the fraction of species $S / S_{\max }$ required to maintain any given function within some proportion $\theta$ of its maximum value $a$.

Evidence-Figure 6 shows the fraction of species used in experiments, $S / S_{\max }$, that are required to maintain producer biomass, nutrient uptake, and decomposition within 50, 75, and $90 \%$ of the maximum possible value. Data are presented as frequency distributions for all studies that fall within 3 standard deviations of the M-M parameter estimates for $a$ and $b$ (i.e., extreme statistical outliers have been omitted). The median values of these distributions suggest that $92 \%$ of the maximum number of species used in experiments would only maintain $50 \%$ of the maximum possible producer biomass (Fig. 6A). To maintain producer biomass at $75 \%$ of its maximum, we would need 2.76× more species than have been used in experiments thus far and $8.27 \times$ more species to maintain biomass within $90 \%$ of its maximum. To maintain nutrient uptake at $50 \%$ of its maximum value, we need $1.28 \times$ more species than have been used in experiments thus far. Numbers increase to $3.83 \times$ and $11.48 \times$ experimental levels of diversity to maintain nutrient uptake at 75 and $90 \%$, respectively. On the other hand, studies of decomposition suggest we need just $18 \%$ of species used in litter experiments to maintain this process at $50 \%$ of its maximum value. $52 \%$ of litter species used to date are required to maintain decomposition with $75 \%$ of the maximum, and $1.56 \times$ more species than have been used in experiments is required to maintain decomposition within $90 \%$ of the maximum value.
Conclusions-When interpreting the results of Fig. 6, two things are important to keep in mind: (1) these predictions come from extrapolated estimates of a saturating function that estimates the maximum of a function as richness goes to infinity. As a result, estimates of $S / S_{\max }$ grow disproportionately large as $\theta \rightarrow 1$, which is the nature of a saturating curve. (2) The functional variables have been expressed on proportional scales to facilitate comparison among studies. As a result, absolute changes in the dependent variables are large at lower values of $\theta$ (say, $\theta=50$ to $75 \%$ ), but diminishingly small at high values (say, $\theta=90$ to $95 \%$ ).

With these caveats in mind, data for two of three processes suggest that previous expert surveys (Schlapfer et al., 1999) have under-estimated the fraction of species required to maintain ecological processes within $75 \%$ of their maximum values (H7, Table 1). The frequency distributions in Fig. 6 suggest that for some experiments, processes are close to saturation within the range of diversity used. This result is particularly true for the experiments of decomposition where $75 \%$ or more the maximum possible values have been captured. In contrast, many experiments that focus on producer biomass and nutrient uptake have yet to approach saturation within the range of species richness studied, and estimates suggest that diversity may be underestimated by as much as $2-10 \times$ depending on what level of function one is interested in. We would caution against taking these numbers too literally at this point, since it is hard to imagine that a researcher could place $10 \times$ more species into a small experimental plot and expect those species to coexist (imagine the experiments at Cedar Creek planting 160 species in a $9 \times 9 \mathrm{~m}$ plot). A literal interpretation would suggest that nature is grossly under-saturated with species and that more diversity is required to maximize processes than currently exists at the scale of experiments. We cannot eliminate this hypothesis with the present data, but two other possibilities seem more likely. The first is that the large estimates of $S / S_{\max }$ reflect some type of probabilistic "sampling" processes. If a researcher were to plant many more species, the actual number of species in a plot would drop to more realistic levels $(\sim 12$ spp per plot, from data in 

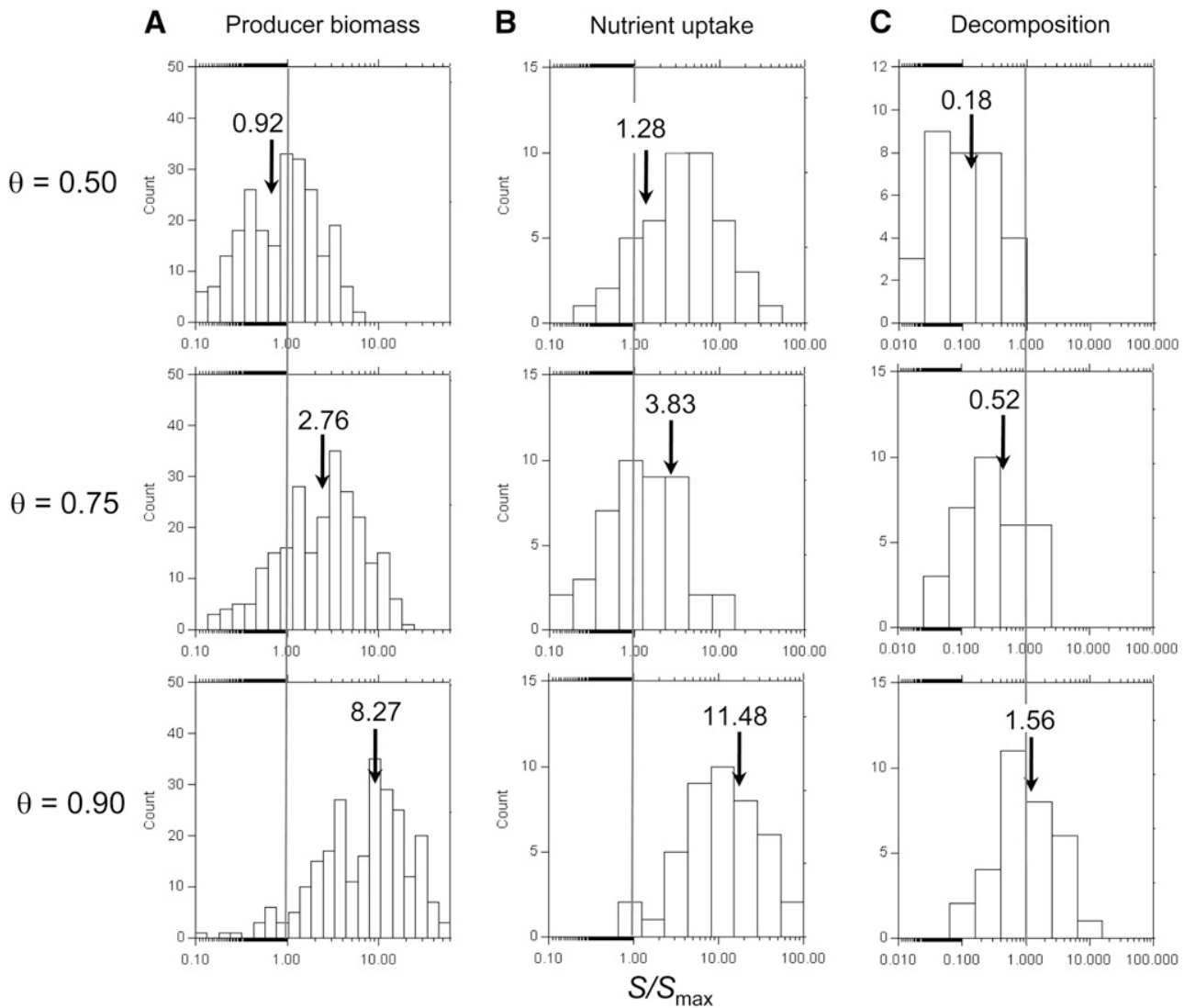

Fig. 6. Preliminary estimates of the fraction of species that are required to maintain a given level of ecosystem functioning. The $x$-axis in each plot shows what fraction of the maximum number of species used in an experiment would be needed to maintain a given proportion of the maximum possible producer biomass (panel A), nutrient uptake (panel B), or decomposition (panel C) in biodiversity experiments (the distribution of values for all experiments is shown as a histogram). The maximum possible function is the extrapolated asymptotic value estimated as the parameter $a$ from fitting data from studies to the Michaelis-Menten functions (i.e., data summarized in Table 3). From this function, the fraction of species required to get within a proportion $\theta$ of the maximum value $a$ was calculated from Eq. (1) in the main text (also see Appendix 1). Solid vertical lines show where the fraction of species $=1$, which is the total number of species that has been used in experiments to date. Median values of the distributions for all studies included in the analyses are noted with arrows.

Tilman et al., 2001), but the greater likelihood of getting highly productive combinations of species would lead to higher productivity overall. Alternatively, curves from the Michaelis-Menten function may provide a satisfactory fit to data within the range of richness used in experiments. But when extrapolating far beyond these levels of richness, the function gives mathematically plausible, but biologically unrealistic numbers of species needed to achieve maximum function. Further work may be needed to generate more realistic estimates of such asymptotic patterns.

Question 8. Are diversity effects "stronger" at larger spatial and/or longer time scales?-Background-More than $60 \%$ of BEF experiments with producers have allowed for less than one generation of growth by the focal populations (Fig. 7). The median study of terrestrial plants has been performed in $3-\mathrm{m}^{2}$ plots, and the median aquatic study in 0.1 -L experimental units. While there are exceptions, it seems safe to say that most of our inferences about biodiversity stem from experiments that have been performed at time scales that are shorter and spatial scales that are smaller than those at which species extinctions actually matter and at which conservation and management efforts take place (also see Naeem, 2001).

Several researchers have proposed that diversity effects in small-scale, short-term experiments may underestimate the im- pacts of diversity loss on ecosystem processes in natural ecosystems (Field, 1995; Cardinale et al., 2004; Duffy, 2009; Hillebrand and Matthiessen, 2009). The assumption is that the larger spatial scales and greater temporal fluctuations that are typical of natural systems incorporate more heterogeneity and more niche opportunities for species to exploit resources than are available in experiments. Consistent with this argument, Cardinale et al. (2007) summarized data from 17 grassland diversity studies that had time-series data and showed that both the net effect of plant richness on plant biomass and the magnitude of complementarity effects increased with the duration of experiments. Stachowicz et al. (2008) found similar trends for a study of marine macroalgae, and Weis et al. (2007) have been able to explain temporal changes in diversity effects for microalgae using models of succession. In contrast to the well-studied aspects of time, few studies have manipulated biodiversity at more than one spatial scale (but see Dimitrakopoulos and Schmid, 2004). As such, the hypothesis that biodiversity becomes more important at larger spatial scales is largely untested.

Evidence-We standardized the duration of studies used in this analysis by the mean generation time of the organisms to estimate the number of generations that a study had run ( $x$-axis, Fig. 7). In addition, we divided the size of the experimental unit 


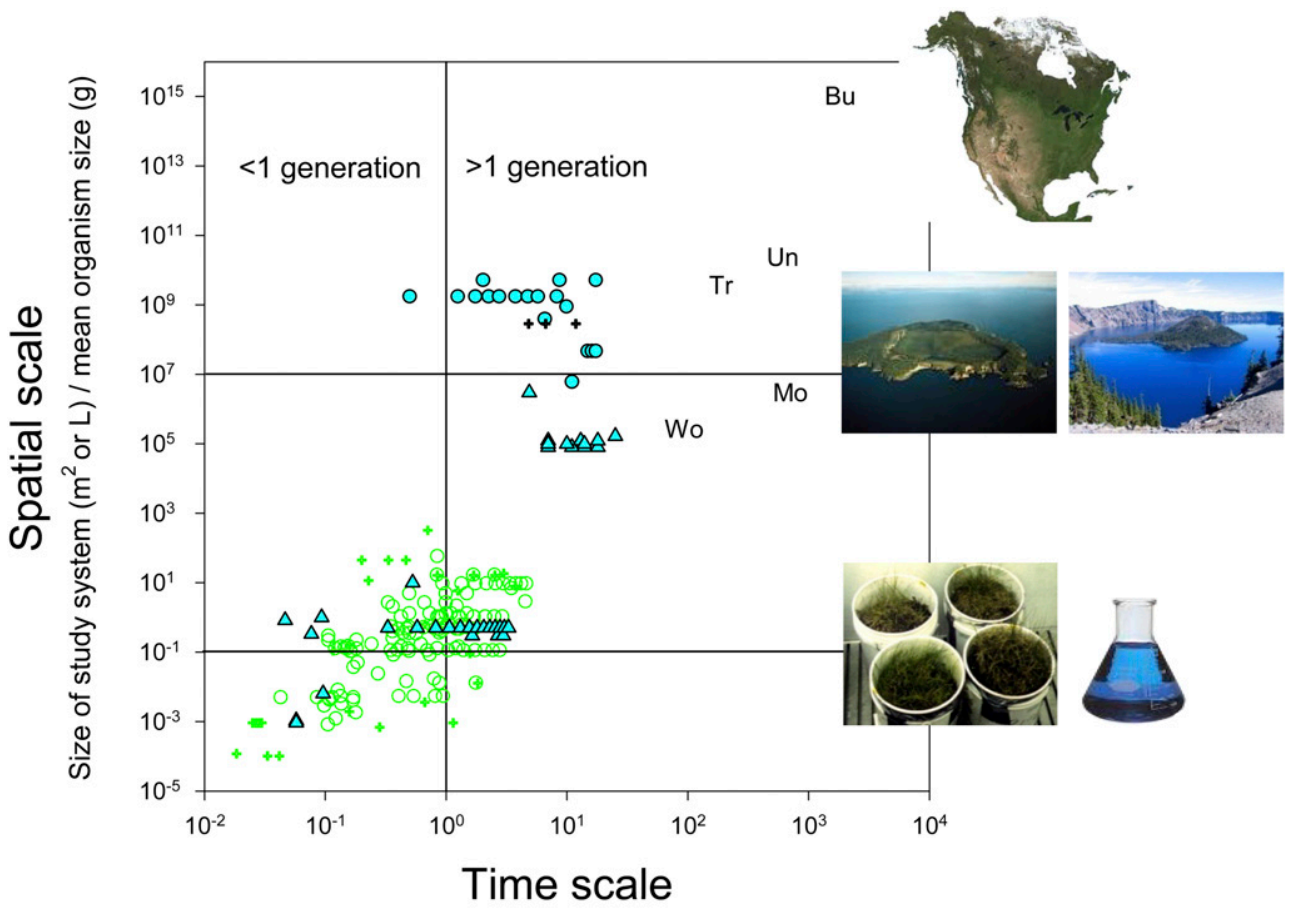

Duration of experiment (d) / mean generation time (d)

\begin{tabular}{|l|l|l|l|}
\hline & $N$ & Time scale & Spatial scale \\
\hline All systems & 438 & $0.18^{\star \star *}$ & $0.01^{\text {ns }}$ \\
\hline All terrestrial & 322 & $0.18^{\star \star *}$ & $0.05^{\star *}$ \\
\hline O grassland plants & 301 & $0.33^{\star \star *}$ & $0.00^{\text {ns }}$ \\
\hline All aquatic & 82 & $0.24^{\star \star}$ & $0.03^{\star}$ \\
\hline O lake algae & 33 & $0.42^{\star}$ & $0.19^{\star *}$ \\
\hline $\boldsymbol{\Delta}$ intertidal algae & 45 & $0.11^{\text {ns }}$ & $0.11^{\text {}}$ \\
\hline
\end{tabular}

Fig. 7. The scales of biodiversity experiments. The $x$-axis in the main plot represents the number of generations that an experiment has run, and the $y$-axis is an index of the spatial scale at which experiments have been performed. Each data point represents a single study-blue symbols are aquatic, green are terrestrial. To place the scale of experiments in context, we plotted the scales at which management and conservation efforts have attempted to mitigate for certain real extinctions: Wo $=$ wolves from Yellowstone National Park, USA, Mo $=$ moa from New Zealand, $\mathrm{Tr}=$ trout from Lake Superior, USA, Un $=$ unionid mussels from the lower Mississippi River, USA, $\mathrm{Bu}=$ various species of butterflies in Europe. In the table below the figure, we show the partial regression coefficients relating the net effect of producer diversity, $\mathrm{LR}_{\text {net }}$, on producer biomass to both the time scale of experiments (after holding spatial scales constant) and the spatial scale of experiments (after holding time scales constant). These partial regression coefficients are shown for differing subsets of existing data, with levels of significance noted as ns $=$ nonsignificant, $* P<0.10, * * P<0.05, * * * P<0.01$.

used in a study by the mean body mass of the focal taxa, producing an index of spatial scale that can be compared across experiments and systems ( $y$-axis, Fig. 7). The methods for generating these data have been previously described in Cardinale et al. (2009c). Because the spatial and temporal scales of studies were strongly correlated (i.e., larger studies usually run longer), we used partial regression analyses to ask how the net diversity effect of producer richness on producer biomass, $\mathrm{LR}_{\text {net }}$, changed as a function of (1) the time scales of experiments after statistically holding spatial scales constant, and (2) the spatial scale of experiments after holding time scales constant.

With few exceptions, the net diversity effect grew stronger with increasing spatial and temporal scales of experiments (Fig. 7, inset table). $\mathrm{LR}_{\text {net }}$ was more consistently related to the time scale of experiments, increasing for nearly every system for which we had sufficient data to evaluate (the exception was intertidal algae). $\mathrm{LR}_{\text {net }}$ increased by a factor of 1.20 to $1.52 \times\left(e^{0.18}\right.$ to $e^{0.42}$ ) for each 10 -fold increase in the number of generations included in an experiment. Relationships between $\mathrm{LR}_{\text {net }}$ and the spatial scale of experiments were less consistent among subsets of data, and were most apparent for aquatic ecosystems (Fig. 7, inset table). $\mathrm{LR}_{\text {net }}$ increased by a factor of 1.03 to $1.21 \times\left(e^{0.03}\right.$ to $\left.e^{0.19}\right)$ for each 10 -fold increase in spatial scales.

Conclusions-Data are generally consistent with the idea that the strength of diversity effects are stronger in experiments that run longer, and in experiments performed at larger spatial scales $(H 8 a, b$, Table 1$)$. The hypothesis that diversity effects 
grow stronger with time has already received substantial support from individual experiments (e.g., Tilman et al., 2001; Stachowicz et al., 2008) and other meta-analyses (e.g., Cardinale et al., 2007). Our analyses extend this conclusion by showing that similar results hold true across studies that span nearly four orders of magnitude in temporal scales and after accounting for statistical correlations between the duration of experiments and their spatial scale. There also appears to be a residual relationship between net diversity effects and the spatial scale of experiments. We have less confidence in the significance and generality of a spatial relationship than we do for temporal scale because (1) the spatial relationships are not as consistent across systems, (2) they tend to be weaker, and (3) unlike the many studies that have time series, few experiments have manipulated diversity at multiple spatial scales to provide an independent test of scaling relationships. Nevertheless, there is a relationship between the magnitude of diversity effects and spatial scale, which warrants further attention.

One important point, which we thank a reviewer for bringing up, is that space and time do not, by themselves, regulate diversity effects. Rather, it is the various forms of environmental heterogeneity that covary with space or time that regulate the performance of species and, in turn, the magnitude of diversity effects. So even while we are seeing a signal that suggests diversity effects grow stronger in larger experiments run for more generations, these represent nothing more than phenomenological correlations. We caution researchers against propagating more blind-faith statements about diversity being more functionally important at larger scales until the time we can identify a solid mechanistic basis for such a claim. The challenge now is to identify and isolate the specific environmental factors that vary systematically with space and time and which of these simultaneously regulate the magnitude of diversity effects.

\section{SUMMARY AND FUTURE DIRECTIONS}

We have summarized the results of 368 independent experiments that manipulated plant or algal species richness in a variety of terrestrial, marine, and freshwater ecosystems. These studies have reported 634 estimates of how the diversity of primary producers impacts the production of plant biomass, uptake of inorganic nutrients, loss of producer tissue to herbivores, and the decomposition of producer litter. On the basis of our analyses of this data set, we are comfortable making the following statements about the functional role of producer diversity in ecosystems:

(1) There is now unequivocal evidence that declining diversity of plants and algae in the world's ecosystems will, on average, lead to decreases in the biomass of producers and their ability to remove inorganic nutrients from soil and water. Preliminary evidence also suggests that declining diversity of primary producers may reduce rates of $\mathrm{O}_{2}$ production and $\mathrm{CO}_{2}$ uptake from the atmosphere; however, the impacts of diversity on rates of primary production and $\mathrm{C}$ sequestration are topics in need of more data.

(2) There is currently no consistent experimental evidence that declining plant or algal diversity will alter the amount of plant biomass that is lost to herbivores. This is not to say that producer diversity does not influence herbivory, as individual studies have shown it does. But the effect has not been in any consistent direction, leading to a distribution of effect sizes that do not differ from zero. Unfortunately, our uncertainty in this conclusion is high due to the low number of studies available and the fact that experimental results seem to conflict with observations in both natural and agricultural ecosystems (Andow, 1991; Hillebrand and Cardinale, 2004; Edwards et al., 2010). Resolving this conflict is a priority for future work.

(3) Limited evidence suggests that, on average, declining diversity of plants may reduce rates of decomposition and the efficiency by which biologically essential elements are recycled back into their inorganic forms. However, the estimated impacts of diversity on decomposition are weak compared to other processes, and most of the significant effects on decomposition come from studies performed in streams. More work is needed to understand mechanisms driving litter diversity effects and why these differ in different ecosystems.

(4) Effects of plant and algal diversity on producer biomass are driven not only by the presence of highly productive species in diverse communities, but also by some form of complementarity among species. Complementarity appears to play the primary role in driving diversity effects in aquatic ecosystems, whereas complementarity and productive species appear equally important in terrestrial ecosystems.

(5) At present, we know little about the biological mechanisms(s) that is (are) responsible for complementarity among species and, as such, ecologists have yet to develop a mechanistic explanation for diversity effects. Although it is often assumed that complementarity effects can be equated with niche partitioning, this is not the case. Future studies will need to augment their use of post hoc statistical attempts to explain patterns, with more direct tests of the mechanisms that are presumed to underlie diversity effects.

(6) Although diverse communities contain species that have complementary effects on ecosystem processes, there is little evidence that diverse polycultures of plants or algae "outperform" their most efficient or productive species. In fact, it is more common for polycultures to produce less biomass, sequester fewer nutrients, and decompose litter more slowly than their most extreme species. This presents a conundrum: how can species be "complementary" in their use of resources and production of biomass, and yet, a diverse community not perform processes any more efficiently than its most efficient species? Some have proposed this is the natural outcome of niche-based coexistence (Loreau, 2004), may be an artifact of the short duration of experiments (Cardinale et al., 2007), may be due to negative selection effects that prevent expression of overyielding (Hooper and Dukes, 2004; Jiang et al., 2008), or represents limitations in our ability to test for transgressive overyielding (Schmid et al., 2008). These hypotheses warrant more investigation.

(7) The form of diversity-function relationships is generally positive but decelerating, and is well described by a saturating Michaelis-Menten curve. This curve suggests that initial losses of species have minimal impacts on a process, but increasing losses lead to accelerating rates of change. From these curves, we can calculate the proportion of species that are required to achieve different levels of the measured processes. Our best estimates suggest that many biodiversity experiments are substantially below saturation in the processes measured at the levels of diversity used. However, extrapolating to the number of species needed to maximize biomass production and nutrient uptake gives potentially unrealistic estimates of alpha diversity, given typical numbers of species found in natural ecosystems. Further resolving these estimates will require more work.

(8) The net effects of producer diversity on producer biomass generally grow stronger as experiments are run for longer 
periods of time. Preliminary evidence also suggests that diversity effects are likely stronger for experiments that are performed at larger spatial scales. Again, this suggests that, if anything, BEF experiments have under-estimated the functional role of producer diversity in ecosystems.

The conclusions above come from more than two decades of experimental work linking species diversity to the functioning of ecosystems. These represent milestones for a field that has made tremendous progress in a relatively short time. However, there are several new questions toward which we must now turn our attention if we are to develop better, more predictive models that can detail the consequences of biodiversity loss. We believe these include the four questions that follow.

Question 9. How do diversity effects documented in experiments scale-up to real ecosystems? - Although the first generation of BEF research has clearly shown that biodiversity has a significant impact on ecological properties, the relevance of $\mathrm{BEF}$ research to conservation and management research continues to be controversial (Srivastava and Vellend, 2005). In part, this is because the results of often highly simplistic experiments have yet to be translated into meaningful predictions about how biodiversity loss will impact ecological processes in realistic systems at appropriate scales. There is now ample evidence that diversity effects grow stronger as studies allow for more generations of growth, and some evidence now suggest that diversity effects grow stronger at larger spatial scales. Such findings corroborate many researchers' intuition (Duffy, 2009; Hillebrand and Matthiessen, 2009) and mathematical models (Loreau et al., 2003; Cardinale et al., 2004).

Even so, there remains a large gap between the scales at which experiments have been performed $\left(\mathrm{cm}^{2}\right.$ to $\mathrm{m}^{2},<1$ to 10 generations) and the scales at which we conserve species or attempt to mitigate for extinction (islands, national parks, watersheds, etc.). Recognizing that we will never perform biodiversity experiments at the truly relevant scales, we believe there is a great need to develop quantitative scaling relationships that can be used to extrapolate the results of BEF experiments and estimate the level of species loss that might alter ecosystem functioning at more relevant scales. We can complement these extrapolations with new experiments that manipulate biodiversity at differing scales, and which explicitly incorporate the forms of spatial and temporal heterogeneity of both the physical environment (e.g., Griffin et al., 2009) and its resources (e.g., Weis et al., 2008) that are thought to moderate species coexistence and, in turn, biodiversity effects. Ideally, the experiments could be used to refine predictions from scaling relationships, and vice versa.

Question 10. Sure, diversity effects are significant. But how strong and important are they compared to other forms of environmental change? - Loss of the world's biodiversity is occurring in the broader context of global environmental change. Human domination of the planet has resulted in climate change, eutrophication, acidification, pollution of soil and water, fragmented landscapes, invasive species, and more (Vitousek et al., 1997). Many of these forms of environmental change have major impacts on the same ecological processes that biodiversity influences. While experts have attempted to rank the relative impacts of different forms of environmental change to prioritize research and policy needs (Rockstrom et al., 2009), such efforts are rarely guided by any actual data. The lack of data is also confounded by the fact that different forms of environmental change are intertwined and mutually dependent. For example, loss of biodiversity is often a byproduct of other forms of change, which suggest that there are potential feedbacks and nonadditivities that we have yet to consider.

Because of these issues, we believe that three goals for the next generation of BEF research are to (1) compare the magnitude of effect sizes for different forms of environmental change, including biodiversity loss, on comparable ecosystem processes, (2) quantify how BEF relationships are altered by other forms of environmental change, and (3) quantify the degree of nonadditive interactions between biodiversity loss and other forms of environmental change. Much progress could be made by merging summaries of different bodies of literature that have already quantified effect sizes for different forms of environmental change. In addition, we could use more experiments that manipulate biodiversity in combination with other forms of environmental change (as in Reich et al., 2001; Fridley, 2003) so that we can compare effect sizes directly, and assess whether impacts on processes are additive or nonadditive. We also need to take greater advantage of new analytical and modeling tools that help tease apart the relative contributions of biodiversity and covarying environmental drivers to natural variation in ecosystems processes - both variation through time (see Grace et al., 2007 for an example), and variation across spatial locations (i.e., the different sites used in BioDepth; Hector et al., 1999).

Question 11. What types of biological diversity have the greatest impact on ecosystem processes-Would conservation and management of ecological functions be better achieved by focusing on genetic, species, functional, or even higher levels of diversity? - Although most $\mathrm{BEF}$ experiments have focused on the functional role of species richness, species are little more than a convenient unit of packaging for all the genetic, trait, and functional variation that ultimately controls ecological functions. And species are themselves organized in populations that change through time and in space across heterogeneous landscapes. In principle, trait variation at any level in this biological hierarchy could influence ecosystem processes through the same suite of mechanisms demonstrated or inferred to operate among species. Indeed, a growing body of evidence suggests that genotypic variation within a species can influence ecological processes with magnitudes that are comparable to those of species richness (Hughes et al., 2008). Cadotte et al. (2008) showed that the evolution of genetic variation among species was even a better predictor of community biomass than species or functional group richness for studies of grassland plants. At the other end of the hierarchy, turnover among genes, populations, or species across habitats within a landscape ( $\beta$-diversity) is known to influence trophic interactions and the stability of food webs (Polis et al., 1997; McCann et al., 2005). But the hypothesis that diversity at the scale of habitats or landscapes controls ecosystem functioning has only recently been tested (see Schindler et al., 2010; Staddon et al., 2010).

If we are to figure out which levels of biological diversity give the most "bang-for-the-buck" in the conservation of ecological functions, we need new types of BEF studies. We need experiments that explicitly manipulate biodiversity at multiple levels, such as might be accomplished by the simultaneous manipulation of genetic clones taken from spatially varying populations for each of several parthenogenic species. Such studies could offer direct quantification of the explanatory power of different forms of biodiversity. We also need studies that demonstrate how much unique variation in a given process can be 
explained by genetic $\rightarrow$ species $\rightarrow$ functional group $\rightarrow$ community $\rightarrow$ landscape-level diversity in natural systems.

Question 12. How does biodiversity simultaneously impact the suite of ecosystem processes that are required to optimize the multifunctionality of diverse ecosystems?-While BEF experiments have historically focused on one process at a time, it is widely recognized that humans depend on natural ecosystems to provide a variety of services and products (MEA, 2005). This has led some to suggest that BEF experiments have underestimated the diversity required to maximize the suite of processes that are required to sustain higher life within ecosystems (Hector and Bagchi, 2007; Gamfeldt et al., 2008; Zavaleta et al., 2010). If correct, how do we estimate the number of species or other forms of diversity that are needed to maximize the multifunctionality of ecosystems? In particular, how frequently do trade-offs occur such that maximizing some processes comes at the expense of others? Conversely, how frequent are synergistic and interdependent interactions among processes?

To rigorously address the importance of multifunctionality, we need to quantify how the effects of different genotypes, species, or other forms of diversity covary in their impacts on different ecological functions. If covariation among diversity effects is strong, then this suggests that a subset of diversity would be sufficient to maximize several processes simultaneously. However, if covariation is weak, this would suggest that more diversity is needed to maximize the rates of several processes at once. We also need to better understand how diversity effects on processes are altered by interactions, both among species and among functions. Specifically, if maximization of particular ecological functions entails reductions in other functions, then biodiversity might impose trade-offs in ecosystem multifunctionality. Conversely, if certain sets of ecosystem processes are synergistic such that increases in one stimulate another (e.g., attraction of pollinators and plant biomass production), then increasing biodiversity may be "catalytic", i.e., able to maximize several ecosystem services at once.

In conclusion-We are struck by the enormous progress that has been made in the field of biodiversity and ecosystem functioning in a relatively short time. It was only a decade ago that a large fraction of researchers wondered whether biodiversity could even matter as an explanatory variable (Schlapfer et al., 1999). We now have the theoretical foundations and sufficiently large data sets that we can say with certainty that biodiversity does indeed regulate several processes that are essential to the functioning of ecosystems and that many of these functions are important for humanity. More important, we now have the sophistication and quantitative detail to provide predictive estimates of the consequences of diversity loss. We are, for the first time, in a realistic position to evaluate the fit of different mathematical expressions that describe diversity effects and to offer concrete predictions about the number of species required to sustain certain ecological processes - at least, at the small scales of experiments. It is not unreasonable to think that in 5-10 years, we will be able to offer quantitative predictions about the ecological impacts of multiple forms of diversity loss at scales that are relevant to conservation and management of the world's biodiversity. But to get to that point, new challenges and new milestones must be met. BEF researchers will need to break out of their traditional experimental designs to get a better handle on mechanisms. Scientists will need to design studies to embrace and try to explain natural variation rather than experimen- tally control it. The field will need to interface more broadly with other disciplines that can say how diversity relates to ecological processes over evolutionary time at the scale of whole ecosystems or larger. These challenges will not be dealt with easily, but the field of BEF research now has all the tools needed to take these next, important steps.

\section{LITERATURE CITED}

AARsSEN, L. W. 1997. High productivity in grassland ecosystems: Effected by species diversity or productive species? Oikos 80 : 183-184.

Andow, D. A. 1991. Vegetational diversity and arthropod population response. Annual Review of Entomology 36: 561-586.

Balvanera, P., A. B. Pfisterer, N. Buchmann, J.S. He, T. NaKashizuka, D. RAFFAELLI, AND B. SCHMID. 2006. Quantifying the evidence for biodiversity effects on ecosystem functioning and services. Ecology Letters 9: 1146-1156.

Boyer, K. E., J. S. Kertesz, ANd J. F. Bruno. 2009. Biodiversity effects on productivity and stability of marine macroalgal communities: The role of environmental context. Oikos 118: 1062-1072.

Bruno, J. F., and B. J. Cardinale. 2008. Cascading effects of predator richness. Frontiers in Ecology and the Environment 6: $539-546$.

Cadotte, M. W., B. J. Cardinale, and T. H. Oakley. 2008. Evolutionary history and the effect of biodiversity on plant productivity. Proceedings of the National Academy of Sciences, USA 105: 17012-17017.

Cardinale, B. J., D. M. Bennett, C. E. Nelson, and K. Gross. 2009a. Does productivity drive diversity or vice versa? A test of the multivariate productivity-diversity hypothesis in streams. Ecology 90: $1227-1241$.

Cardinale, B. J., E. Duffy, D. Srivastava, M. Loreau, M. Thomas, And M. EMmERSON. 2009b. Towards a food-web perspective on biodiversity and ecosystem functioning. In S. Naeem, D. Bunker, M. Loreau, A. Hector, and C. Perring [eds.], Biodiversity and human impacts, 105-120. Oxford University Press, Oxford, UK.

Cardinale, B. J., A. R. Ives, and P. Inchausti. 2004. Effects of species diversity on the primary productivity of ecosystems: Extending our spatial and temporal scales of inference. Oikos 104: 437-450.

Cardinale, B. J., D. S. Srivastava, J. E. Duffy, J. P. Wright, A. L. Downing, M. Sankaran, and C. Jouseau. 2006. Effects of biodiversity on the functioning of trophic groups and ecosystems. Nature 443: 989-992.

Cardinale, B. J., D. S. Srivastava, J. E. Duffy, J. P. Wright, A. L. Downing, M. Sankaran, C. Jouseau, et al. 2009c. Effects of biodiversity on the functioning of ecosystems: A summary of 164 experimental manipulations of species richness. Ecology 90: 854 (data paper).

Cardinale, B. J., J. P. Wright, M. W. Cadotte, I. T. Carroll, A. Hector, D. S. Srivastava, M. Loreau, and J. J. Weis. 2007. Impacts of plant diversity on biomass production increase through time due to complementary resource use: A meta-analysis. Proceedings of the National Academy of Sciences, USA 104: 18123-18128.

Carroll, I. T., B. J. Cardinale, and R. M. Nisbet. In press. Niche and fitness differences relate the maintenance of diversity to ecosystem function. Ecology doi:10.1890/10-0302.1.

Chase, J. M., AND M. A. Leibold. 2003. Ecological niches: Linking classical and contemporary approaches. University of Chicago Press, Chicago, Illinois, USA

Chesson, P. 2000. Mechanisms of maintenance of species diversity. Annual Review of Ecology and Systematics 31: 343-366.

Covich, A. P., M. C. Austen, F. Barlocher, E. Chauvet, B. J. Cardinale, C. L. Biles, P. Inchausti, et AL. 2004. The role of biodiversity in the functioning of freshwater and marine benthic ecosystems. Bioscience 54: 767-775.

Dimitrakopoulos, P. G., AND B. SChmid. 2004. Biodiversity effects increase linearly with biotope space. Ecology Letters 7: 574-583.

DufFy, J. E. 2002. Biodiversity and ecosystem function: The consumer connection. Oikos 99: 201-219. 
DufFY, J. E. 2009. Why biodiversity is important to the functioning of real-world ecosystems. Frontiers in Ecology and the Environment 7: 437-444.

Duffy, J. E., B. J. Cardinale, K. E. France, P. B. McIntyre, E. ThÉbault, and M. Loreau. 2007. The functional role of biodiversity in ecosystems: Incorporating trophic complexity. Ecology Letters 10: 522-538.

Edwards, K. F., K. M. Aquilino, R. J. Best, K. L. Sellheim, and J. J. Stachowicz. 2010. Prey diversity is associated with weaker consumer effects in a meta-analysis of benthic marine experiments. Ecology Letters 13: 194-201.

Ehrlich, P. R., AND A. H. Ehrlich. 1981. Extinction: The causes and consequences of the disappearance of species. Random House, New York, New York, USA.

Field, C. B. 1995. Productive capacity and biomass accumulation. In U. N. E. Programme [ed.], Global biodiversity assessment, 402-406. Cambridge University Press, Cambridge, UK

Fox, J. W. 2005. Interpreting the 'selection effect' of biodiversity on ecosystem function. Ecology Letters 8: 846-856.

FridLEY, J. D. 2003. Diversity effects on production in different light and fertility environments: An experiment with communities of annual plants. Journal of Ecology 91: 396-406.

Gamfeldt, L., H. Hillebrand, and P. R. Jonsson. 2008. Multiple functions increase the importance of biodiversity for overall ecosystem functioning. Ecology 89: 1223-1231.

Gartner, T. B., and Z. G. Cardon. 2004. Decomposition dynamics in mixed-species leaf litter. Oikos 104: 230-246.

Grace, J. B., M. T. Anderson, M. D. Smith, E. Seabloom, S. J. Andelman, G. Meche, E. Weiner, Et AL. 2007. Does species diversity limit productivity in natural grassland communities? Ecology Letters 10: 680-689.

GRIFFIn, J. N., S. R. Jenkins, L. GAMFeldt, D. Jones, S. J. HAwKINS, AND R. C. Thompson. 2009. Spatial heterogeneity increases the importance of species richness for an ecosystem process. Oikos 118: 1335-1342.

Grinnell, J. 1917. The niche-relationship of the California thrasher. The Auk 34: 427-433.

Hattenschwiler, S., A. V. Tiunov, and S. Scheu. 2005. Biodiversity and litter decomposition in terrestrial ecosystems. Annual Review of Ecology, Evolution, and Systematics 36: 191-218.

Hector, A. 1998. The effect of diversity on productivity: Detecting the role of species complementarity. Oikos 82: 597-599.

Hector, A., AND R. BAGCHI. 2007. Biodiversity and ecosystem multifunctionality. Nature 448: 188-190.

Hector, A., B. Schmid, C. Beierkuhnlein, M. C. Caldeira, M. Diemer, P. G. Dimitrakopoulos, J. A. Finn, et al.. 1999. Plant diversity and productivity experiments in European grasslands. Science 286: $1123-1127$.

Hedges, L. V., J. Gurevitch, and P. S. Curtis. 1999. The metaanalysis of response ratios in experimental ecology. Ecology 80 $1150-1156$.

Hillebrand, H., and B. J. Cardinale. 2004. Consumer effects decline with prey diversity. Ecology Letters 7: 192-201.

Hillebrand, H., and B. Matthiessen. 2009. Biodiversity in a complex world: Consolidation and progress in functional biodiversity research. Ecology Letters 12: 1405-1419.

Hooper, D. U., F. S. Chapin, J. J. Ewel, A. Hector, P. Inchausti, S. LAVOREL, J. H. LAWTON, ET AL. 2005. Effects of biodiversity on ecosystem functioning: A consensus of current knowledge. Ecological Monographs 75: 3-35.

HoOper, D. U., AND J. S. DukEs. 2004. Overyielding among plant functional groups in a long-term experiment. Ecology Letters 7: 95-105.

Hughes, A. R., B. D. Inouye, M. T. J. Johnson, N. Underwood, AND M. Vellend. 2008. Ecological consequences of genetic diversity. Ecology Letters 11: 609-623.

Huston, M. A. 1997. Hidden treatments in ecological experiments: Reevaluating the ecosystem function of biodiversity. Oecologia 110 449-460.

Hutchinson, G. E. 1967. A treatise on limnology, vol. 2, Introduction to lake biology and the limnoplankton. Wiley, New York, New York, USA.
JiAng, L., Z. Pu, AND D. R. Nemergut. 2008. On the importance of the negative selection effect for the relationship between biodiversity and ecosystem functioning. Oikos 117: 488-493.

Jones, C. G., J.H.LAwton, AND M. ShaChaK. 1994. Organisms as ecosystem engineers. Oikos 69: 373-386.

Levine, J. M., AND J. HilleRisLambers. 2009. The importance of niches for the maintenance of species diversity. Nature 461: 254-257.

LoREAU, M. 1998. Separating sampling and other effects in biodiversity experiments. Oikos 82: 600-602.

LoreaU, M. 2004. Does functional redundancy exist? Oikos 104: 606-611.

Loreau, M., AND A. Hector. 2001. Partitioning selection and complementarity in biodiversity experiments. Nature 412: 72-76.

Loreau, M., N. MouQuet, and A. GonZalez. 2003. Biodiversity as spatial insurance in heterogeneous landscapes. Proceedings of the National Academy of Sciences, USA 100: 12765-12770.

Loreau, M., S. Naeem, P. Inchausti, J. Bengtsson, J. P. Grime, A. Hector, D. U. Hooper, ET AL. 2001. Biodiversity and ecosystem functioning: Current knowledge and future challenges. Science 294: 804-808.

McCann, K. S., J. B. Rasmussen, and J. Umbanhowar. 2005. The dynamics of spatially coupled food webs. Ecology Letters 8: 513-523.

Millennium Ecosystem Assessment. 2005. Ecosystems and human well-being: Synthesis. Island Press, Washington, D.C., USA.

NAEEM, S. 1998. Species redundancy and ecosystem reliability. Conservation Biology 12: 39-45.

NAEEM, S. 2001. Experimental validity and ecological scale as tools for evaluating research programs. In R. H. Gardner, W. M. Kemp, V. S. Kennedy, and J. E. Petersen [eds.], Scaling relationships in experimental ecology, 223-250. Columbia University Press, New York New York, USA

NAEEM, S. 2002. Ecosystem consequences of biodiversity loss: The evolution of a paradigm. Ecology 83: 1537-1552.

Naeem, S., L. J. Thompson, S. P. Lawler, J. H. Lawton, and R. M. Woodfin. 1994. Declining biodiversity can alter the performance of ecosystems. Nature 368: 734-737.

Niklaus, P. A., P. W. Leadley, B. Schmid, and C. Korner. 2001. A longterm field study on biodiversity $\times$ elevated $\mathrm{CO}_{2}$ interactions in grassland. Ecological Monographs 71: 341-356.

Northrield, T. D., G. B. Snyder, A. R. Ives, And W. E. Snyder. 2010. Niche saturation reveals resource partitioning among consumers. Ecology Letters 13: 338-348.

Petchey, O. L. 2003. Integrating methods that investigate how complementarity influences ecosystem functioning. Oikos 101: 323-330.

Petchey, O. L., A. Hector, and K. J. Gaston. 2004. How do different measures of functional diversity perform? Ecology 85: 847-857.

PiotTo, D. 2008. A meta-analysis comparing tree growth in monocultures and mixed plantations. Forest Ecology and Management 255: 781-786.

Polis, G. A., W. B. ANDERson, And R. D. Holt. 1997. Toward an integration of landscape and food web ecology: The dynamics of spatially subsidized food webs. Annual Review of Ecology and Systematics 28 289-316.

Reich, P. B., J. Knops, D. Tilman, J. Craine, D. Ellsworth, M. Tuoelker, T. LeE, ET AL. 2001. Plant diversity enhances ecosystem responses to elevated $\mathrm{CO}_{2}$ and nitrogen deposition. Nature 410: 809-812.

Reinhardt, L., D. Jerolmack, B. J. Cardinale, V. Vanacker, and J. Wright. 2010. Dynamic interactions of life and its landscape: Feedbacks at the interface of geomorphology and ecology. Earth Surface Processes and Landforms 35: 78-101.

Rockstrom, J., W. Steffen, K. Noone, A. Persson, F. S. Chapin, E. F. Lambin, T. M. Lenton, ET AL.. 2009. A safe operating space for humanity. Nature 461: 472-475.

Schindler, D. E., R. Hilborn, B. Chasco, C. P. Boatright, T. P. Quinn, L. A. Rogers, And M. S. Webster. 2010. Population diversity and the portfolio effect in an exploited species. Nature 465 : 609-612.

Schlapfer, F., B. Schmid, And L. Seidl. 1999. Expert estimates about effects of biodiversity on ecosystem processes and services. Oikos 84: $346-352$. 
Schmid, B., P. Balvanera, B. J. Cardinale, J. Godbold, A. B. Pfisterer, D. Raffaelli, M. Solan, and D. S. Srivastava. 2009a. Consequences of species loss for ecosystem functioning: A metaanalysis of data from biodiversity experiments In S. Naeem, D. Bunker, M. Loreau, A. Hector, and C. Perring [eds.], Biodiversity and human impacts, 14-29. Oxford University Press, Oxford, UK.

Schmid, B., A. Hector, P. SaHA, AND M. Loreau. 2008. Biodiversity effects and transgressive overyielding. Journal of Plant Ecology 1: 95-102.

SCHMid, B., J. Joshi, AND F. SCHLAPFer. 2001. Empirical evidence for biodiversity-ecosystem functioning relationships. In A. P. Kinzig, S. W. Pacala, and D. Tilman [eds.], The functional consequences of biodiversity: Empirical progress and theoretical extensions., 120-150. Princeton University Press, Princeton, New Jersey, USA.

Schmid, B., A. B. Pfisterer, P. Balvanera, AND W. K. Michener. 2009 b. Effects of biodiversity on ecosystem, community, and population variables reported 1974-2004. Ecology 90: 853.

Schulze, E. D., AND H. A. Mooney. 1993. Biodiversity and ecosystem function. Springer-Verlag, New York, New York, USA.

Schwartz, M. W., C. A. Brigham, J. D. Hoeksema, K. G. Lyons, M. H. Mills, and P. J. van Mantgem. 2000. Linking biodiversity to ecosystem function: Implications for conservation ecology. Oecologia 122: 297-305.

Srivastava, D. S., B. J. Cardinale, A. L. Downing, J. E. Duffy, C. Jouseau, M. Sankaran, and J. P. Wright. 2009. Diversity has stronger top-down than bottom-up effects on decomposition. Ecology 90: 1073-1083.

Srivastava, D. S., ANd M. Vellend. 2005. Biodiversity-ecosystem function research: Is it relevant to conservation? Annual Review of Ecology, Evolution, and Systematics 36: 267-294.

Stachowicz, J., J. F. Bruno, AND J. E. DufFy. 2007. Understanding the effects of marine biodiversity on communities and ecosystems. Annual Review of Ecology, Evolution, and Systematics 38: 739-766.

Stachowicz, J. J., M. Graham, M. E. S. Bracken, and A. I. Szoboszlai. 2008. Diversity enhances cover and stability of seaweed assemblages: The role of heterogeneity and time. Ecology 89: 3008-3019.

Staddon, P., Z. Lindo, P. D. Crittenden, F. Gilbert, and A. GonZalez. 2010. Connectivity, non-random extinction and ecosystem function in experimental metacommunities. Ecology Letters 13: $543-552$.

Sterner, R. W., ANd J. J. Elser. 2002. Ecological stoichiometry: The biology of elements from molecules to the biosphere. Princeton University Press, Princeton, New Jersey, USA.
Stocker, R., C. Korner, B. Schmid, P. A. Niklaus, and P. W. Leadley. 1999. A field study of the effects of elevated $\mathrm{CO}_{2}$ and plant species diversity on ecosystem-level gas exchange in a planted calcareous grassland. Global Change Biology 5: 95-105.

Tilman, D. 1999. The ecological consequences of changes in biodiversity: A search for general principles. Ecology 80: 1455-1474.

Tilman, D. 2000. Causes, consequences, and ethics of biodiversity. Nature 405: 208-211.

Tilman, D., And J. A. Downing. 1994. Biodiversity and stability in grasslands. Nature 367: 363-365.

Tilman, D., D. Lehman, and K. Thompson. 1997. Plant diversity and ecosystem productivity: Theoretical considerations. Proceedings of the National Academy of Sciences, USA 94: 1857-1861.

Tilman, D., P. B. Reich, J. Knops, D. Wedin, T. Mielke, and C. Lehman. 2001. Diversity and productivity in a long-term grassland experiment. Science 294: 843-845.

Tilman, D., D. Wedin, AND J. Knops. 1996. Productivity and sustainability influenced by biodiversity in grassland ecosystems. Nature 379: 718-720.

Trenbath, B. R. 1974. Biomass productivity of mixtures. Advances in Agronomy 26: 177-210.

VAndermeer, J. H. 1989. The ecology of intercropping. Cambridge University Press, Cambridge, UK.

Vitousek, P. M., H. A. Mooney, J. Lubchenco, and J. M. Melillo. 1997. Human domination of Earth's ecosystems. Science 277: 494-499.

Weis, J. J., B. J. Cardinale, K. J. Forshay, and A. R. Ives. 2007. Effects of species diversity on community biomass production change over the course of succession. Ecology 88: 929-939.

Weis, J. J., D. Madrigal, and B. J. Cardinale. 2008. Effects of algal species richness on the production of community biomass in homogeneous verses heterogeneous environments. PLOS ONE 3: e2825.

Worm, B., E. B. Barbier, N. Beaumont, J. E. Duffy, C. Folke, B. S. HALPERN, J. B. C. JACKSON, ET AL. 2006. Impacts of biodiversity loss on ocean ecosystem services. Science 314: 787-790.

Wright, J. P., AND C. G. JoNES. 2006. The concept of organisms as ecosystem engineers ten years on: Progress, limitations, and challenges. Bioscience 56: 203-209.

Zavaleta, E. S., J. R. Pasari, K. B. Hulvey, and G. D. Tilman. 2010. Sustaining multiple ecosystem functions in grassland communities requires higher biodiversity. Proceedings of the National Academy of Sciences, USA 107: 1443-1446. 


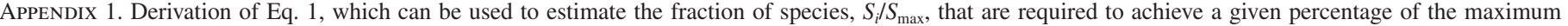
theoretical function performed by a group of producers.

Begin with the Michaelis-Menten function:

$$
\frac{Y_{\mathrm{p}}}{Y_{1}}=\frac{a S}{b+S} .
$$

The left side of Eq. 2 is the magnitude of any process $Y$ measured in polyculture and standardized relative to the average monoculture, $S$ is species richness, $a$ is the maximum theoretical value (i.e., the extrapolated estimate for the asymptote), and $b$ is the half-saturation constant (the number of species required to achieve $50 \%$ of $a$ ). If changes in species richness are expressed on a proportional scale, $S_{i} / S_{\max }$, where $S_{\max }$ is the highest number of species used in an experiment, then Eq. 2 becomes:

$$
\frac{Y_{\mathrm{P}}}{Y_{1}}=\frac{a\left(S_{i} / S_{\max }\right)}{b+\left(S_{i} / S_{\max }\right)} .
$$

Assuming we want to know the fraction of species required to achieve $\theta$ percent of the maximum theoretical function $a$, Eq. 3 becomes

$$
\theta a=\frac{a\left(S_{i} / S_{\max }\right)}{b+\left(S_{i} / S_{\max }\right)} .
$$

Multiplying both sides by the denominator $b+\left(S_{i} / S_{\max }\right)$, and then solving for $S_{i} / S_{\max }$, we get:

$$
\theta a b+\theta a\left(S_{i} / S_{\max }\right)=a\left(S_{i} / S_{\max }\right)
$$

$$
\theta a b=a\left(S_{i} / S_{\max }\right)-\theta a\left(S_{i} / S_{\max }\right)
$$

$$
\theta a b=\left(S_{i} / S_{\max }\right)(a-\theta a)
$$

$$
S_{i} / S_{\max }=\frac{\theta a b}{a-\theta a}
$$

For any data fit to the Michaelis-Menten function in Eq. 1, the rearrangement given by Eq. 8 can be used to calculate the fraction of species, $S_{i} / S_{\max }$ required to achieve $\theta$ percent of the maximum theoretical (i.e., asymptotic) function. 